\title{
Microglia depletion diminishes key elements of the leukotriene pathway in the brain of Alzheimer's Disease mice
}

\author{
J. Michael ${ }^{1,2+}$, M. S. Unger ${ }^{1,2+}$, R. Poupardin 2,3 , P. Schernthaner ${ }^{1,2}$, H. Mrowetz ${ }^{1,2}$, J. Attems ${ }^{4}$ and L. Aigner ${ }^{1,2,5^{*}}$ (D)
}

\begin{abstract}
Leukotrienes (LTs) contribute to the neuropathology of chronic neurodegenerative disorders including Alzheimer's Disease (AD), where they mediate neuroinflammation and neuronal cell-death. In consequence, blocking the action of Leukotrienes (LTs) ameliorates pathologies and improves cognitive function in animal models of neurodegeneration. Surprisingly, the source of Leukotrienes (LTS) in the brain is largely unknown. Here, we identified the Leukotriene (LT) synthesis rate-limiting enzyme 5-Lipoxygenase (5-Lox) primarily in neurons and to a lesser extent in a subpopulation of microglia in human Alzheimer's Disease (AD) hippocampus brain sections and in brains of APP Swedish PS1 dE9 (APPPS1) mice, a transgenic model for Alzheimer's Disease (AD) pathology. The 5-Lipoxygenase (5-Lox) activating protein (FLAP), which anchors 5-Lipoxygenase (5-Lox) to the membrane and mediates the contact to the substrate arachidonic acid, was confined exclusively to microglia with the entire microglia population expressing 5-Lipoxygenase activating protein (FLAP). To define the contribution of microglia in the Leukotriene (LT) biosynthesis pathway, we ablated microglia using the colony stimulating factor 1 receptor (CSF1R) inhibitor PLX5622 in wildtype (WT) and APP-PS1 mice. Microglia ablation not only diminished the expression of FLAP and of the Leukotriene (LT) receptor Cysteinylleukotriene receptor 1 (CysLTR1), as expected based on their microglia cell type-specific expression, but also drastically reduced 5Lipoxygenase (5-Lox) mRNA expression in the brain and its protein expression in neurons, in particular in wildtype (WT) mice. In conclusion i) microglia are key in Leukotriene (LT) biosynthesis, and ii) they regulate neuronal 5-Lipoxygenase (5-Lox) expression implying a yet unknown signaling mechanism between neurons and microglia.
\end{abstract}

Keywords: Leukotrienes, Cysteinyl-leukotrienes, Alzheimer's disease, Microglia, RNAseq

\section{Introduction}

Leukotrienes (LTs) are elevated in the brain in aging, after injury, and in neurodegenerative diseases such as Alzheimer's Disease (AD) [1-4]. Increased levels of LTs contribute to age- and disease-related brain pathologies such as i) neuroinflammation and microglia / astroglia activation [57], ii) neuronal damage [8, 9], and iii) blood-brain-barrier

\footnotetext{
*Correspondence: ludwig.aigner@pmu.ac.at

${ }^{\dagger}$ J. Michael and M. S. Unger contributed equally to this work.

'Institute of Molecular Regenerative Medicine, Paracelsus Medical University, Strubergasse 21, 5020 Salzburg, Austria

${ }^{2}$ Spinal Cord Injury and Tissue Regeneration Center Salzburg (SCI-TReCS), Paracelsus Medical University, Salzburg, Austria

Full list of author information is available at the end of the article
}

(BBB) permeability [10-12]. Therefore, LT signaling has been recognized as therapeutic target in acute and chronic neurodegenerative diseases (for review see $[13,14]$ ). In the context of $\mathrm{AD}$, various in vivo studies demonstrated that genetic and pharmacological interventions reducing LT production or LT signaling ameliorate pathological burdens such as amyloid and tau load and improve cognitive function [2, 15-18]. Moreover, human genetics data illustrated that a single nucleotide polymorphism in the gene for 5-lox activating protein (FLAP), a key protein in the activation of $\mathrm{LT}$ synthesis, correlates with an increased risk for AD suggesting that LTs might indeed contribute to AD development [19]. Vice versa, a Norwegian population-based study 
suggested that Montelukast, an approved anti-asthmatic drug and LT receptor antagonist, might lower the risk for developing dementias [20]. Finally, a recent case study with 17 dementia patients illustrated beneficial effects of Montelukast on cognition and agitation [21] suggesting that blockade of LT synthesis or LT signaling might indeed be a therapeutic approach for the treatment of dementias such as $\mathrm{AD}$ (reviewed in [13]).

LT biosynthesis is part of the complex metabolism of poly-unsaturated fatty acids (PUFAs), which also includes the production of anti-inflammatory substances (lipoxins, resolvins, maresin and protectin), as well as proinflammatory substances like prostaglandins and thromboxanes (Fig. 1). LTs originate from omega-6 polyunsaturated arachidonic acid (AA), which is converted to LTA4 mediated by the enzyme 5-lipoxygenase (5-Lox) and the activating protein FLAP. These key elements need to be in physical proximity and form a complex to initiate the first reaction of the LT biosynthesis pathway [22] From LTA4 either LTB4 or cysteinyl-LTs (CysLTs) are generated. CysLTs bind with different affinities to the cysteinyl LT receptor 1 and 2 (CysLT1R [24], CysLT2R [25]) and G-protein coupled receptor 17 (GPR17) [26]. 5Lox, together with other lipoxygenases (12-Lox and 15Lox) also plays a role in other pathways of PUFA metabolism, for example in the formation of resolvins starting from the omega-3 poly-unsaturated docosahexaenoic (DHA) or eicosapentaenoic (EPA) acids, which, like AA are also cleaved from plasma membranes by the enzyme Phospholipase $\mathrm{A}_{2}$ (PLA $)$ (Fig. 1).

In the periphery LTs are generated by leukocytes [28] with subgroups having different capacities to produce either LTB4 (neutrophils) or CysLTs (eosinophils, basophils) or both (macrophages, mast cells) [29]. In the brain, although there is an age- and disease related increase in LTs, and effects of LTs via CyslTR1 and 2 on various brain cells

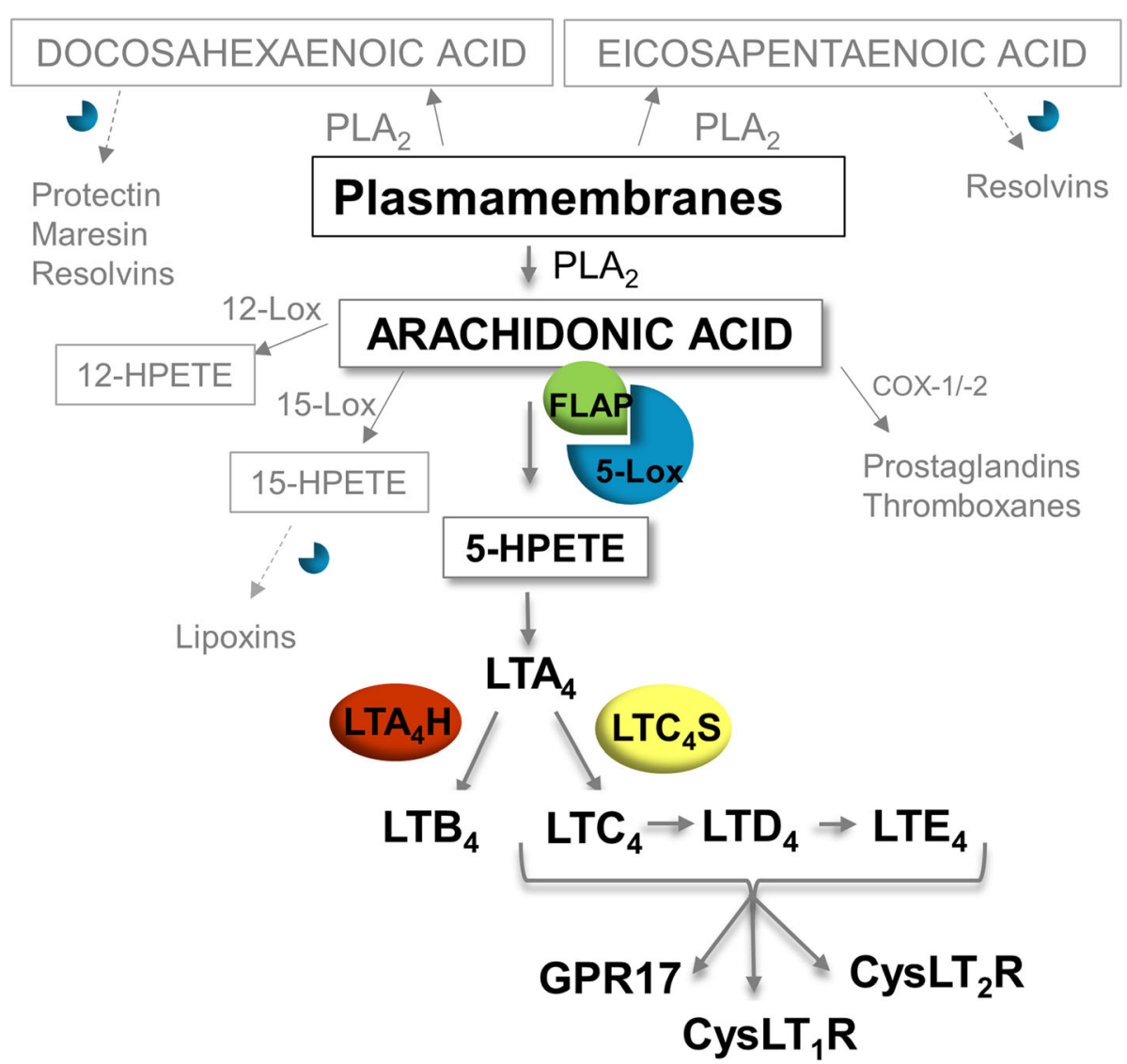

Fig. $1 \mathrm{LT}$ biosynthesis is part of metabolism of the omega 6 polyunsaturated arachidonic acid (AA), which is cleaved from plasmamembranes by phospholipase $A_{2}\left(P L A_{2}\right)$. AA is a substrate for several lipoxygenases. For the production of LTs it is first converted into 5-hydroxy-peroxyeicosatetraenoic acid (5-HPETE) and afterwards into LTA4, both steps mediated by a complex of the enzyme 5-lipoxygenase (5-Lox) and 5lipoxygenase activating protein (FLAP) [22]. From LTA4 arise either Leukotriene B4 (LTB4) formed by epoxide hydrolase or Leukotriene C4 (LTC4) formed by LTC4 synthase, which can be further metabolized to LTD4 and LTE4 [23]. LTC4, LTD4 and LTE4 are summarized under the term cysteinyl-leukotrienes (CysLTs). CysLTs display different affinities towards the receptors cysteinyl-leukotriene receptor 1 and 2 (CysLT1R [24]), CysLT2R [25]) and G-protein coupled receptor 17 (GPR17 [26, 27]). The enzyme 5-Lox is also involved in some steps of biosynthesis of specialized pro-resolving mediators from omega 3 poly-unsaturated fatty acids (DHA - docosahexaenoic acid; EPA - eicosapentaenoic acid) 
are well documented (reviewed in [14]), the cellular source of LTs is rather unexplored. Obviously, such knowledge might improve the further understanding of the underlying molecular and cellular pathomechanisms, moreover, it might foster therapy development for diseases such as AD. Prominent neuronal expression of 5-Lox and of FLAP mRNA was described in the hippocampus and in various other regions of the rat brain using in-situ hybridization [30]. Here, we investigated expression of 5-Lox, the rate limiting enzyme in LT production, and of FLAP, the 5-Lox activating protein, in the brain of wild-type (WT) and of transgenic AD mice (APP-PS1 mice) as well as in human post-mortem brain specimen of $\mathrm{AD}$ patients. We identified microglia as the only cell type in the brain to express FLAP, while 5-Lox was predominantly expressed in neurons with some expression also in a population of microglia. As an experimental approach, we ablated microglia cells for 4 weeks from the brain of WT and APP-PS1 transgenic mice and analyzed the molecular consequences in terms of the LT pathway.

\section{Material and methods Compounds}

PLX5622 was provided by Plexxikon Inc. and formulated in AIN-76A standard chow by Research Diets Inc. at $1200 \mathrm{mg} / \mathrm{kg}$, as previously described [31, 32].

\section{Animals}

Female and male APP Swedish PS1 dE9 mice (reviewed in [33] and [34]) expressing a chimeric mouse/human mutant amyloid precursor protein (Mo/HuAPP695swe) and a mutant human presenilin 1 (PS1-dE9) both directed to CNS neurons under the prion protein promoter (available by Jackson Laboratory, http://www.jax.org/strain/005864) were used. Mice were housed at the Paracelsus Medical University Salzburg in groups under standard conditions at a temperature of $22^{\circ} \mathrm{C}$ and a $12 \mathrm{~h}$ light/dark cycle with ad libitum access to standard food and water. Animal care, handling, genotyping and experiment were approved by local ethical committees (BMWFW-66.019/0032-WF/V/3b/2016).

For this study, 12-months old animals were treated for 28 days with PLX5622 chow. Age-matched nontransgenic mice, derived from the breeding of APP Swedish PS1 dE9 (herein abbreviated as APP-PS1) were used as control animals (WT). All animals were adapted to control chow 2 weeks before introducing the PLX5622 chow. The 4 experimental groups consisted of WT and APP-PS1 mice which received control chow and WT and APP-PS1 mice which received the PLX5622 chow for a total of 28 days (see Fig. 4a).

\section{Perfusion and tissue sectioning}

After 28 days of treatment the mice were anesthetized by intraperitoneal injection of a ketamine $(20.5 \mathrm{mg} / \mathrm{ml}$,
Richter Pharma), xylazine $(5.36 \mathrm{mg} / \mathrm{ml}$, Chanelle) and acepromacine $(0.27 \mathrm{mg} / \mathrm{ml}$, VANA $\mathrm{GmbH})$ mixture as previously published [35]. Afterwards their thoracic cavity was opened with an incision caudal to the sternum. Animals were manually perfused through the left ventricle with ice cold HBSS containing $15 \mathrm{mM}$ HEPES (all from Thermofisher) and $0.5 \%$ glucose (Sigma) to wash out the blood. Afterwards mice were decapitated and brains were extracted from the skull. One total brain hemisphere was immersed in $4 \%$ paraformaldehyde (in $0.1 \mathrm{M}$ sodium phosphate solution, $\mathrm{pH}=7.4$ ) at $4{ }^{\circ} \mathrm{C}$ for 2 days for fixation before being washed in PBS and transferred into $30 \%$ sucrose for cryoprotection. When fully soaked with sucrose brain hemispheres were cut in $40 \mu \mathrm{m}$ slices on dry ice using a sliding microtome (Leika) dividing one brain hemisphere in representative 10ths of the brain. Sections were stored at $-20^{\circ} \mathrm{C}$ in cryoprotectant solution (ethylene glycol, glycerol, $0.1 \mathrm{M}$ phosphate buffer $\mathrm{pH}$ 7.4, 1:1:2 by volume).

\section{Fluorescence immunohistochemistry (IHC)}

Fluorescence immunohistochemistry of mouse tissue was performed on free-floating sections as previously described [36, 37]. Antigen retrieval was performed depending on the used primary antibody by steaming the sections for $15-20 \mathrm{~min}$. in citrate buffer $(\mathrm{pH}=6.0$, Sigma). When we used a primary mouse antibody on mouse tissue we used a mouse on mouse kit (Vector laboratories MOMKit BMK-2202, Szabo-Scandic) according to the manufacturer's instructions. The following primary antibodies were used overnight: goat anti-Iba1 (1:500, Abcam), mouse anti-5-Lox (1:50, BD biosciences), monoclonal and polyclonal rabbit anti-5-Lox (1:100, Abcam), goat antiFLAP (1:150) and rabbit anti-FLAP (1:100, both Novus Biologicals), chicken anti-GFAP (1:2000, Abcam) and guinea pig anti-NeuN (1:700, Millipore). Sections were extensively washed in PBS and incubated for $3 \mathrm{~h}$ at RT in secondary antibodies all diluted 1:1000. The following secondary antibodies were used: donkey anti-goat Alexa Fluor 647, donkey anti-guinea pig Alexa Flour 647, donkey anti-chicken Alexa Fluor 488 (Jackson Immuno Research) and donkey anti-rabbit Alexa Fluor 488, donkey antirabbit Alexa Fluor 568 and donkey anti-mouse Alexa Fluor 568 (all Invitrogen/Life Technologies). Nucleus counterstaining was performed with $4^{\prime} .6^{\prime}$-diamidino-2phenylindole dihydrochloride hydrate (DAPI $1 \mathrm{mg} / \mathrm{mL}, 1$ : 2000, Sigma). Tissue sections were additionally treated with $0.2 \%$ Sudan Black (Sigma) in $70 \%$ ethanol for $2 \mathrm{~min}$ to reduce the autofluorescence in tissue from old animals [38]. After this treatment the sections were extensively washed in PBS and mounted onto microscope glass slides (Superfrost Plus, Thermo Scientific). Brain sections were cover slipped semi-dry in ProLong Gold Antifade Mountant (Life technologies). 


\section{Quantification of $\mathrm{Iba1}^{+} / 5-\mathrm{Lox}^{+}$and $\mathrm{Iba1}^{+} / 5-$ Lox $^{-}$cell numbers in mouse hippocampus}

3 confocal $z$-stack images at 20x magnification of different hippocampi per animal were taken and the number of $\mathrm{Iba}^{+} / 5-\mathrm{Lox}^{+}$and $\mathrm{Iba}^{+} / 5-\mathrm{Lox}^{-}$cells were counted using Fiji (ImageJ 1.52p). The mean of 3 images per animal was calculated. Only cells with cell nucleus and clearly visible cell soma were taken for analysis. Percentages of $\mathrm{Iba}^{+} / 5$ - $\mathrm{Lox}^{+}$and $\mathrm{Iba}^{+} / 5$-Lox ${ }^{-}$cell numbers in total $\mathrm{Iba}^{+}$cell counts were calculated $(n=5$ animals/ group).

\section{Quantification of percentage (\%) 5-lox staining}

The overall percentage of 5-Lox staining per image was calculated for 3 confocal $\mathrm{z}$-stack images per mouse, all taken at 20x magnification with exact same microscope settings. Images were transformed to maximum intensity projections and a threshold for 5-Lox signals was manually set. We used the analyze particle tool from Fiji (ImageJ $1.51 \mathrm{~h})$ to analyze the number and area $\left(\mu \mathrm{m}^{2}\right)$ of 5 Lox positive particles. We calculated the sum of 5-Lox positive particle areas $\left(\mu \mathrm{m}^{2}\right)$ per image and calculated the percentage (\%) of staining in respect to the total area of the image $\left(\mu \mathrm{m}^{2}\right)$. The mean of 3 images per animal was calculated ( $n=5$ animals/group).

\section{Human FFPE tissue}

For qualitative and quantitative analysis of FLAP and 5Lox immunoreactivity we used $7 \mu \mathrm{m}$ hippocampal sections from formalin-fixed paraffin embedded human brain samples which were obtained from the Newcastle Brain Tissue Resource (NBTR) in accordance with Newcastle University ethics board and ethical approval awarded by The Joint Ethics Committee of Newcastle and North Tyneside Health Authority (reference: 08/ H0906/136). Used samples are listed in Supplementary Table 1).

Irrespective of clinical diagnoses, all brains underwent neuropathological examination according to a routine protocol that uses standardized neuropathological scoring/grading systems, including neurofibrillary tangle (NFT) Braak staging [39, 40] Consortium to Establish a Registry for Alzheimer's Disease (CERAD) scores [41] Newcastle/McKeith Criteria for Lewy body disease [42], National Institute on Aging - Alzheimer's Association (NIA-AA) guidelines [43] and Thal phases of amyloid $\beta$ deposition [44].

For double staining of human brain tissue an ImmPRESS Duet Double Staining HRP/AP Polymer Kit from Szabo-Scandic was used according to manufacturer's instructions. In short, after deparaffinization, antigen retrieval and blocking of endogenous peroxidase activity slides were incubated overnight with the following primary antibodies: mouse anti-5-Lox (1:50, BD Biosciences), rabbit anti-Iba1 (1:1000, Abcam) or rabbit anti-FLAP (1: 100 , Novus Biologicus). For staining slides were first incubated with $\mathrm{DAB} \mathrm{EqV}$ for $2 \mathrm{~min}$, followed by incubation with Vector Red for 30 min (according to protocol ImmPRESS Duet Double Staining HRP/AP Polymer Kit, Szabo-Scandic).

Immunohistochemical stained human brain sections were analyzed using a Virtual Slide Microscope VS120 with the Olympus VS-ASW.L100 software (both from Olympus).

\section{Quantification of $\mathrm{lba}^{+} / 5-\mathrm{lox}^{+}$and $\mathrm{lba} 1^{+} / 5-\mathrm{lox}{ }^{-}$cell numbers in human hippocampus tissue}

Two images/regions of interest with exact same size were selected from the hippocampal dentate gyrus per patient sample. $\mathrm{Iba}^{+} / 5-\mathrm{Lox}^{+}$and $\mathrm{Iba}^{+} / 5-\mathrm{Lox}^{-}$cell numbers were counted using Fiji (ImageJ, version: 2.0.0.rc-69/1.52p) and the mean of 2 images per patient was calculated. Only cells with cell nucleus and clearly visible cell soma were taken for analysis. Percentages of $\mathrm{Iba}^{+} /$ 5 -Lox ${ }^{+}$and $\mathrm{Iba}^{+} / 5$-Lox ${ }^{-}$cell numbers in total $\mathrm{Iba}^{+}$cell counts were calculated and presented as pie charts $(n=$ $3-5$ /group).

\section{Confocal microscopy and image processing}

For imaging the Confocal Laser Scanning Microscopes LSM700 and LSM710 from Zeiss were used and gratefully provided by the microscopy core facility of SCITReCS (Spinal Cord Injury and Tissue Regeneration Center Salzburg). Images were taken with the ZEN 2011 SP3 or SP7 (black edition) software (Zeiss). Images were taken as confocal z-stacks using 20x, 40x, 63x oil magnification with 0.5 or 0.6 zoom and combined to merged maximum intensity projections. For qualitative analysis 2-3 animals per group were immunohistologically stained and analyzed. For quantitative analysis 5 animals per group were stained and analyzed. All images were edited and processed with the ZEN 2012 (blue edition) software (version 1.1.2.0) and Microsoft PowerPoint. 3D Render was performed using Imaris Software (version 9.1.2, Bitplane).

\section{RNA isolation and gene expression analysis}

To detect mRNA levels of microglia and the LT signaling pathway in different brain regions of 12-months old mice, the total RNA was extracted from mouse hippocampus and cortex. After manual perfusion, animals were decapitated and the tissue of interest was dissected of one brain hemisphere. Brain samples were immediately transferred to RNA later (Sigma) and stored at $-80^{\circ} \mathrm{C}$. Tissue was homogenized in $1 \mathrm{ml}$ Trizol (TRI ${ }^{\oplus}$ Reagent; Sigma). For phase separation, $150 \mu \mathrm{l}$ of 1 -bromo-3-chloropropane (Sigma) were added, vortexed and centrifuged $(15 \mathrm{~min}$. at $12.000 \times \mathrm{g}$ at $\left.4{ }^{\circ} \mathrm{C}\right)$. After transferring the aqueous phase 
into a new tube $1 \mu \mathrm{l} \mathrm{GlycoBlue} \mathrm{e}^{\mathrm{ma}}$ (Invitrogen) and $500 \mu \mathrm{l} 2$ Propanol p.A. (Millipore) were added and vortexed. To obtain RNA, samples were centrifuged (10 min. at $12000 \mathrm{x}$ g at $4{ }^{\circ} \mathrm{C}$ ). The pellet was washed with $1 \mathrm{ml} 75 \%$ ethanol, dried and re-suspended in $30 \mu \mathrm{l}$ RNase-free water (prewarmed to $55^{\circ} \mathrm{C}$ ). cDNA was synthesized using the iScript Reverse Transcription Supermix (Bio-Rad). Quantitative gene expression analyses were performed using TaqMan RT-PCR technology. Technical duplicates containing 10 ng of reverse transcribed RNA were amplified with the GoTAQ Probe qPCR Master Mix (Promega) using a twostep cycling protocol $\left(95^{\circ} \mathrm{C}\right.$ for $15 \mathrm{~s}, 60^{\circ} \mathrm{C}$ for $60 \mathrm{~s}$; $40 \mathrm{cy}$ cles, Bio-Rad CFX 96 Cycler). The following validated exon-spanning gene expression assays were employed: As housekeepers PSMD4 (Mm.PT.56.13046188) and Heatr3 (Mm.PT.56.8463165; both Integrated DNA Technologies) were used. Quantification analyses were performed with qBase Plus (Biogazelle) using geNorm algorithms for multi-reference gene normalization. Bars are represented as mean with SEM ( $n=5-8$ per group).

Following primers were used: Alox5ap (Mm.PT.58.5140995), Alox5 (Mm.PT.58.30176779), LTC4S (Mm.PT.58.5813470), CysLT1R (Mm.PT.58.55581316), CysLT2R (Mm.PT.58.41 658034) and GPR17 (Mm.PT.56a.7204101) all from Integrated DNA Technologies.

\section{RNA sequencing analysis \& bioinformatics}

Whole transcriptome analysis was performed by Qiagen Genomic Services from total RNA isolated from hippocampal brain regions of 5 animals per group. Analysis was performed in accordance to the company protocols outlined as follows: The library preparation was done using $\mathrm{TruSeq}^{\circ}$ Stranded mRNA Sample preparation kit (Illumina inc). The starting material (500 ng) of total RNA was mRNA enriched using the oligodT bead system. The isolated mRNA was subsequently fragmented using enzymatic fragmentation. Then first strand synthesis and second strand synthesis were performed and the double stranded cDNA was purified (AMPure XP, Beckman Coulter). The cDNA was end repaired, 3' adenylated and Illumina sequencing adaptors ligated onto the fragments ends, and the library was purified (AMPure $\mathrm{XP}$ ). The mRNA stranded libraries were pre-amplified with PCR and purified (AMPure XP). The libraries size distribution was validated and quality inspected on a Bioanalyzer 2100 or BioAnalyzer 4200 tapeStation (Agilent Technologies). High quality libraries are pooled based in equimolar concentrations based on the Bioanalyzer Smear Analysis tool (Agilent Technologies). The library pool(s) were quantified using qPCR and optimal concentration of the library pool used to generate the clusters on the surface of a flowcell before sequencing on a NextSeq500) instrument (50 cycles) according to the manufacturer instructions (Illumina Inc.). Quality control of raw sequencing data was conducted using FastQC tool [45]. Reads were then mapped to the genome (Mus musculus genome GRCm38) using bowtie2 (version 2.2.2, [46]. Reads that overlap with genes were then counted using HTSEQ tool (version 0.11.2, [47], $-m$ intersection-nonempty $-s$ no $-i$ gene_id $-t$ exon). Expression values of protein coding genes were first normalized and differential expression analysis between the different groups was conducted using Deseq2 [48]. Genes were considered significantly differentially transcribed with an adjusted $p$-value $<0.05$ (Benjamini \& Hochberg multiple testing correction). Genes were annotated using biomaRt package [49].

\section{Statistics}

For statistical analysis the Prism 5-8 software (Graph$\mathrm{Pad}$ ) was used. The data were tested for normal distribution with the Kolmogorov-Smirnov test. For comparison of two groups an unpaired t test was performed. For comparison of more than two groups, one-way analysis of variance (ANOVA) was used with Tukey's or Bonferroni's multiple comparison test as a post-hoc test. The data were depicted as mean and standard error of the mean (SEM) or standard deviation (SD) with a 95\% confidence interval as indicated in the respective figure legends. $P$ values of $p<0.0001$ and $p<0.001$ were considered extremely significant $\left(* * \cdots *\right.$ or $\left.{ }^{* * *}\right), p<0.01$ very significant $(* *)$ and $p<0.05$ significant $(*)$.

\section{Results}

\section{Cell-type specific 5-Lox and FLAP expression in AD and} $A D$ transgenic mouse brains

LTs play a pivotal role in AD pathology, yet it is unclear which cell types are involved in LT biosynthesis in the brain. We performed immunohistochemical analysis for the key enzyme 5-Lox and its activating protein FLAP in brains from human AD patients and age-matched nonpathological controls (see Supplementary Table 1 for clinical and pathological characterization) (Fig. 2). In the hippocampus 5-Lox was predominantly detected in neurons of the granular layer of the dentate gyrus (Fig. 2a) as well as in CA1-3 regions (data not shown). Additionally, we observed low 5-Lox immunoreactivity in some cells, outside of the granular layer, which were according to their morphology most likely of glial identity. In contrast, FLAP was found specifically in non-neuronal cells with glial appearance (Fig. 2b) and was not observed in the granular cell neurons of the dentate gyrus (also not in CA1-3 brain regions - data not shown). FLAP/5-Lox double staining illustrates that 5-Lox stratifies the FLAP expressing cells into a 5-Lox negative (Fig. 2c, arrows) and a 5-Lox positive (Fig. 2c, asterisks) subpopulation. Anticipating that the non-neuronal 5-Lox positive cells might be microglia, we performed double staining of 5- 


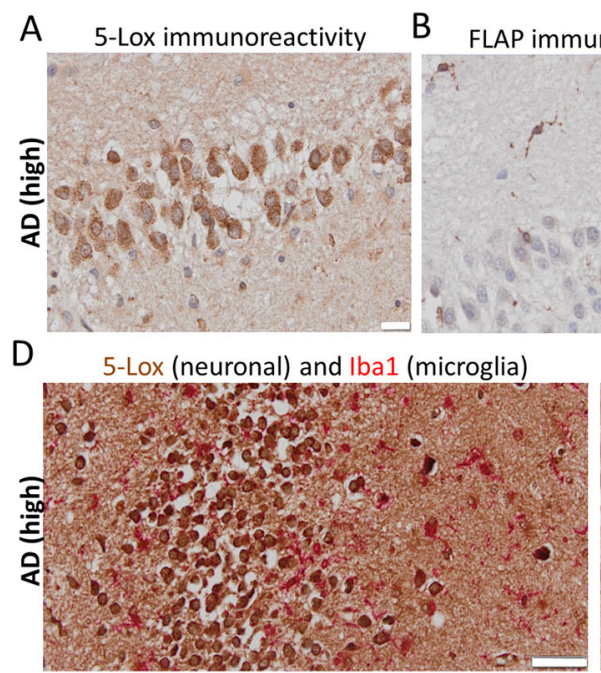

$\mathrm{E}$

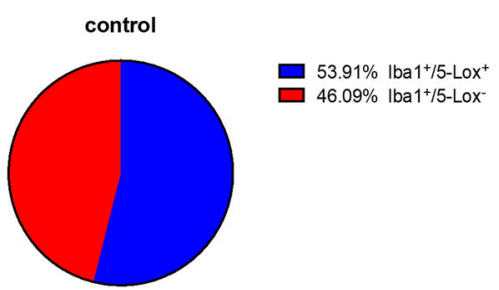

C FLAP and 5-Lox immunoreactivity

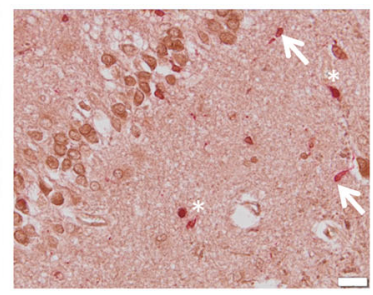

5-Lox (neuronal) and Iba1 (microglia)

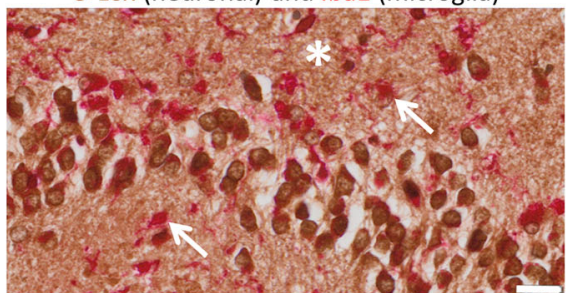

$\mathrm{F}$

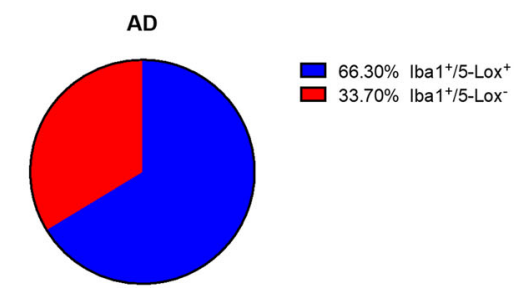

Fig. 2 Immunohistochemical analysis for 5-Lox and FLAP expression in human AD brain. a 5-Lox immunoreactivity (using monoclonal 5-Lox antibody from BD Biosciences \#610694) in human post-mortem AD (high, Braak 6) hippocampus specimen. 5-Lox staining was prominent in cells of the granular cell layer in the dentate gyrus. b FLAP was expressed in cells with glial cell morphology but not in neurons. c Double staining of 5-Lox with FLAP revealed only minor coexpression of 5-Lox in FLAP positive cells (arrows). Asterisks indicate double positive cells. d Double staining of 5-Lox with microglia marker Iba1 showed that non-neuronal 5-Lox expression is associated to some microglia cells (asterisk). Arrows indicate microglia without 5-Lox expression. e Percentage of Iba $1^{+} / 5$-Lox ${ }^{+}$

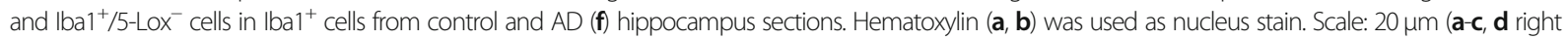
image), $50 \mu \mathrm{m}$ (d, left image)

Lox with Iba1, a classical microglia marker (Fig. 2d). This identified a 5-Lox positive (Fig. 2d, asterisk) and a 5-Lox negative (Fig. 2d, arrows) microglia subpopulation. The quantitative analysis revealed that in nonpathological age-matched controls approximately half of the Iba $1^{+}$population was positive for 5 -Lox immunoreactivity (Fig. 2e), while in $\mathrm{AD}$ samples about $2 / 3$ of the microglia were 5-Lox positive (Fig. 2f). This suggests that in the context of $\mathrm{AD}$, more microglia might be in the position to synthesize LTs.

To corroborate the human data and to stratify our results in a transgenic AD mouse model, we performed immunofluorescence stainings for 5-Lox and FLAP in 13 months old WT and APP-PS1 mice, an age with already advanced pathology (as shown in [36]). We first evaluated several 5-Lox antibodies and their immunoreactivity in neurons and microglia cells (Table 1). As in the human brain specimen, in the granular layer of the dentate gyrus all 5-Lox antibodies showed pre-dominant immunoreactivity in neurons in WT and APP-PS1 mice (example shown in Fig. 3a). While 5-Lox immunoreactivity was more diffuse in the granular layer of WT brain sections, it was dense and more compact in APP-PS1 brains. In addition to the neuronal expression, some Iba1 positive microglia cells (Fig. 3b) as well as GFAP positive astrocytes (Fig. 3c) stained for 5-Lox in WT and APP-PS1 mice. In contrast to the 5-Lox immunoreactivity, but as in the human samples, FLAP staining was confined to microglia (Fig. 3d) and not detected in neurons. We used two different FLAP antibodies from different species (see Table 1) revealing no FLAP immunoreactivity in neurons of the granular cell layer. As all microglia cells were FLAP positive, we can conclude that a microglia subpopulation expresses both FLAP and 5-Lox, particularly observed in APP-PS1 mice. Nevertheless, the vast majority of 5-Lox is predominantly found in neurons.

\section{Microglia ablation reduced elements of the LT synthesis pathway}

To determine the contribution that microglia might play for LT signaling in the brain, we performed a microglia ablation experiment and analyzed its consequences on the LT pathway. 12 months old APP-PS1 transgenic 
Table 1 Tested 5-Lox and FLAP antibodies on mouse brain tissue and their immunoreactivity in neurons and/or microglia cells. aa $=$ amino acid $;-=$ no, $+=$ mild,$++=$ moderate and $+++=$ strong immunoreactivity

\begin{tabular}{|c|c|c|c|c|c|c|}
\hline Antibody (host species) & Dilution & Reactivity & Epitope/antigen & Neurons & Microglia & Others \\
\hline polyclonal Abcam \#ab39347 (rabbit) & $1: 100$ & $\begin{array}{l}\text { mouse, rat, hamster, } \\
\text { human, pig }\end{array}$ & human 5-Lox aa. 130-149 & ++ & ++ & + \\
\hline monoclonal Abcam \#ab169755 (rabbit) & $1: 100$ & mouse, rat, human & human 5-Lox aa. 100-200 & ++ & + & - \\
\hline $\begin{array}{l}\text { monoclonal BD Biosciences \#610694 } \\
\text { (mouse) }\end{array}$ & $1: 50$ & $\begin{array}{l}\text { chicken, human, rat, } \\
\text { mouse }\end{array}$ & human 5-Lox aа. 442-590 & +++ & - & - \\
\hline $\begin{array}{l}\text { polyclonal Novus Biologicals NBP1- } \\
84666 \text { (rabbit) }\end{array}$ & 1:100 & human, rat & recombinant protein & - & +++ & - \\
\hline $\begin{array}{l}\text { polyclonal Novus Biologicals NB300- } \\
891 \text { (goat) }\end{array}$ & $1: 150$ & human, mouse, rat & $\begin{array}{l}\text { peptide corresponding to human FLAP } \\
\text { (C-terminus) }\end{array}$ & - & ++ & - \\
\hline
\end{tabular}
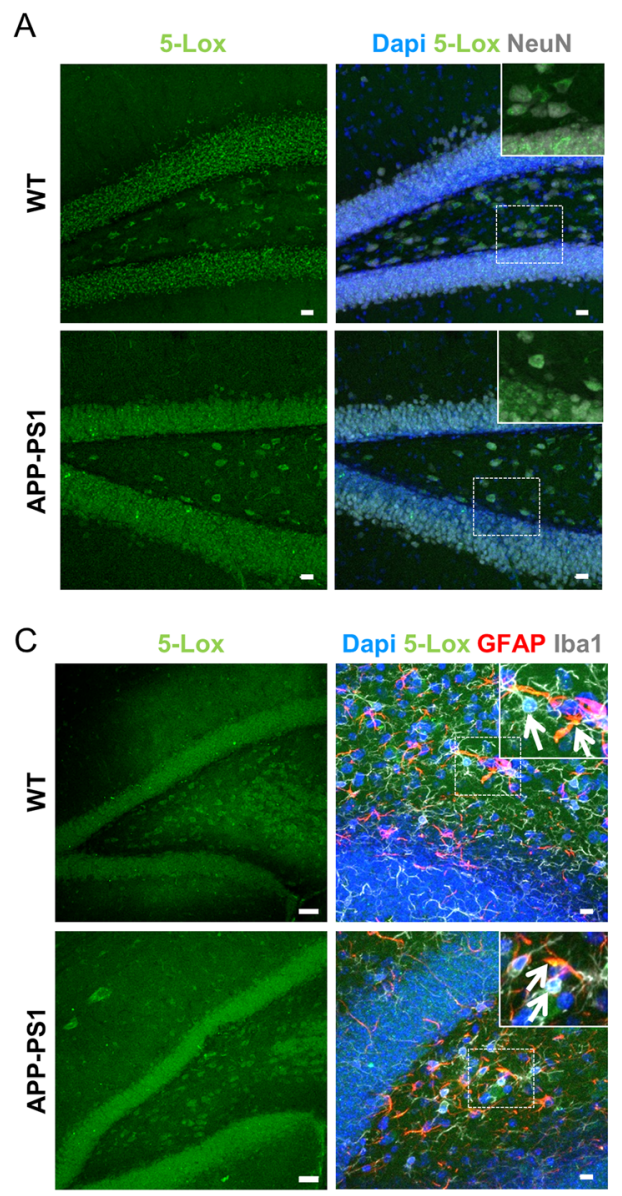

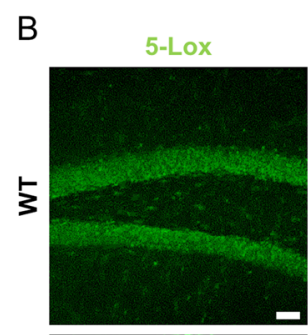

Dapi 5-Lox Iba1
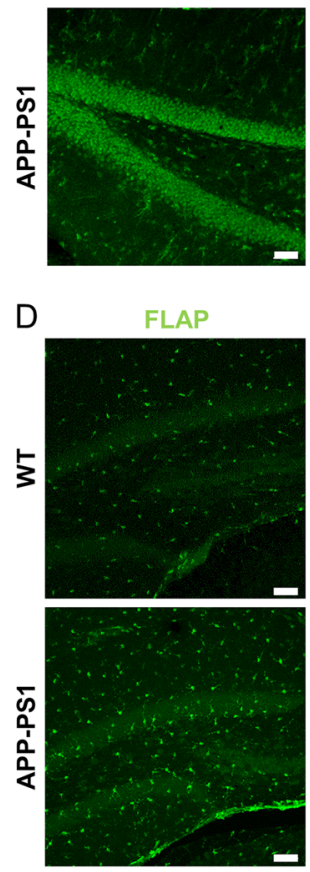

Dapi FLAP Iba1

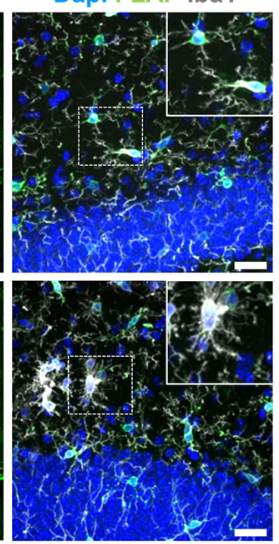

Fig. 3 Immunohistochemical analysis for 5-Lox and FLAP expression in WT and APP-PS1 mouse brains. a In mouse brains the majority of 5-Lox (green, monoclonal 5-Lox antibody from Abcam \#ab169755) immunoreactivity was observed in the granular layer of the dentate gyrus and colocalized with NeuN (white). b 5-Lox immunoreactivity (green, using polyclonal 5-Lox antibody from Abcam \#ab39347) was also observed outside the granular layer in particular in APP-PS1 mice and co-localized with some Iba1 positive microglia (white) cells of WT and APP-PS1 transgenic mice (inserts). c Besides co-expression of 5-Lox (green, using polyclonal 5-Lox antibody from Abcam \#ab39347) in some microglia cells, also GFAP (red) positive astrocytes showed immunoreactivity for 5-Lox in WT and APP-PS1 mice (inserts). d FLAP (green, polyclonal FLAP antibody from Novus Biologicals \#NBP1-84666) was ubiquitously expressed in lba1 positive microglia cells (white) in WT and APP-PS1 transgenic mice. Dapi (a-d) was used as nucleus stain. Scale: $20 \mu \mathrm{m}$ (b-d right images), $50 \mu \mathrm{m}$ (a-d left images) 
mice with already advanced pathology including increased neuroinflammation were compared to agematched WT mice. To specifically ablate microglia cells in the brain we used the small molecule compound PLX5622, that is a potent inhibitor of the colonystimulating factor 1 receptor (CSF1R) [50]. CSF1R inhibitors are widely used to study the role of microglia in several diseases [51-53] including neurodegenerative disease as $\mathrm{AD}[31,32,50,54]$, and we and others previously showed that four weeks of treatment with the CSF1R inhibitor PLX5622 depleted microglia in WT and APP-PS1 mice [31, 32, 35]. In this previous experiment, we had treated APP-PS1 and WT mice with either control or PLX5622 chow for a total of 28 days (Fig. 4a). The treatment had strongly reduced numbers of Iba1 positive microglia in the hippocampus and cortex of WT and APP-PS1 (Fig. 4b) as we had previously published (total number of Iba1+ cells in hippocampus: WT
$78.63 \pm 11.67, \quad$ WT + PLX5622 $13.88 \pm 8.25, \quad$ APP-PS1 $145.63 \pm 27.21$, APP-PS1 + PLX5622 $43.63 \pm 17.59$; cortex: WT $68.71 \pm 10.01$, WT + PLX5622 $5.42 \pm 4.79$, APPPS1 141.04 \pm 23.77 , APP-PS1 + PLX5622 $45.46 \pm 14.65$ ) [35]. To further confirm microglia ablation, we also used the recently identified microglia specific marker TMEM119 [55]. Indeed, TMEM119 immunoreactivity was diminished in PLX5622 treated animals (Fig. 4b). Similar findings were observed in the cortex (Supplementary Figure 1). A small fraction of Iba1 positive cells with altered cell morphology survived the 4 weeks of PLX5622 treatment, especially in the brains of APP-PS1 mice, as we and others had already previously described $[32,35]$.

After 28 days of PLX5622 treatment total RNA was isolated from the hippocampus and further processed to RNA sequence analysis (RNAseq). The transcriptomic data showed that microglia genes such as $\operatorname{Mrc1}(=\mathrm{CD} 206)$,

\section{A}

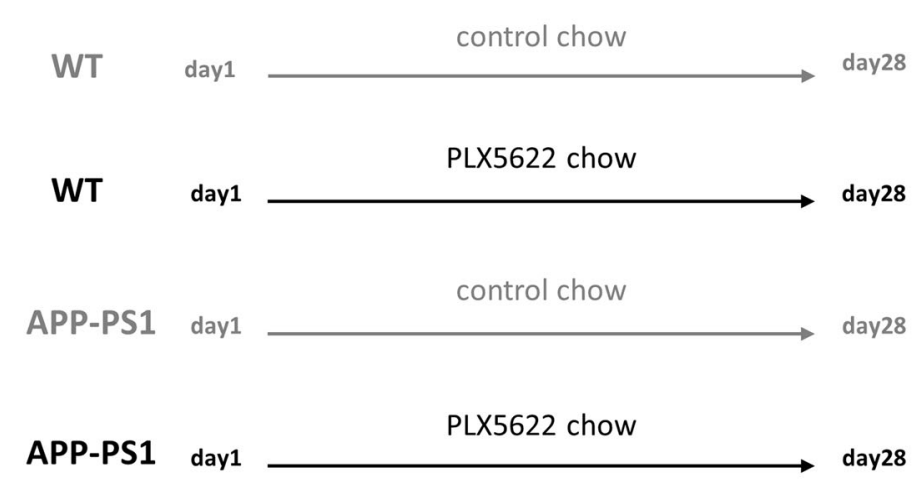

B

hippocampus
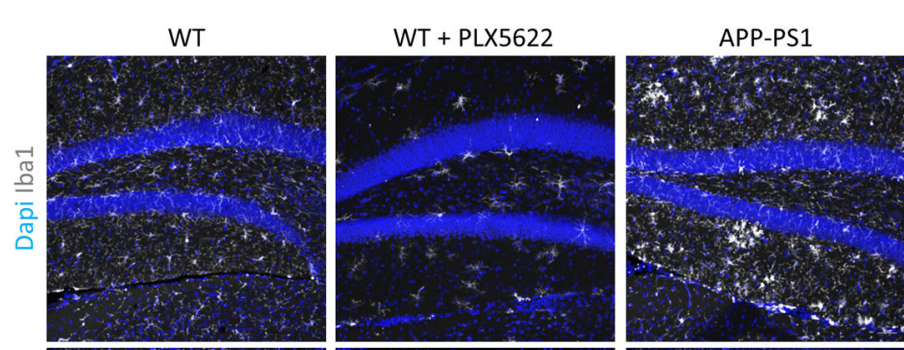

APP-PS1 + PLX5622
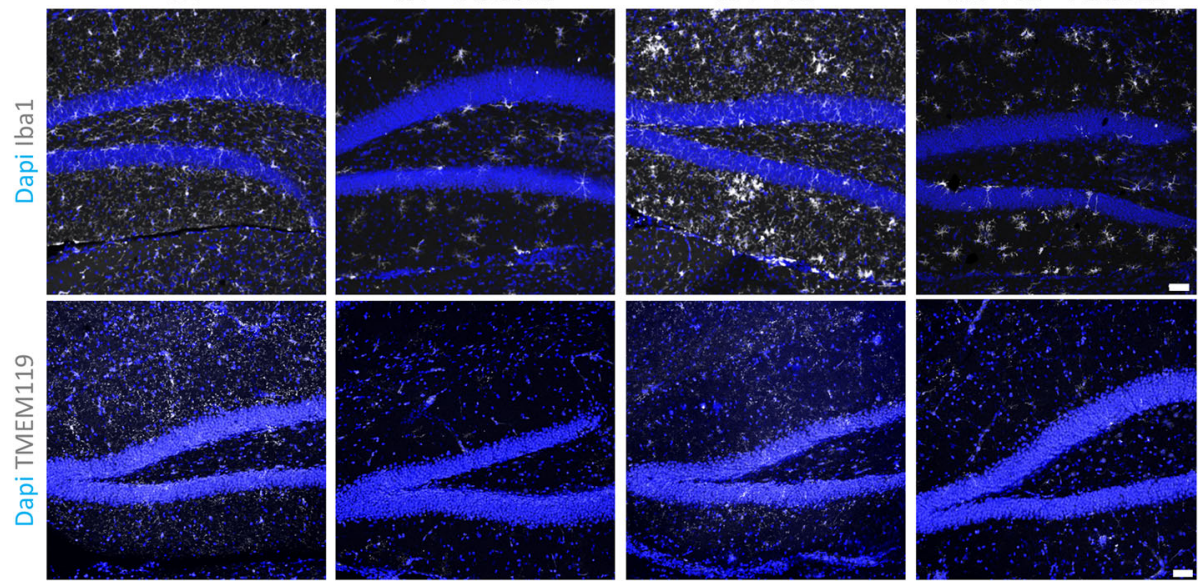

Fig. 4 Experimental design of microglia ablation via CSFR1 inhibition. a 12 month old mice were treated with the CSF1R inhibitor PLX5622 for a total of 28 days. Treatment was applied in form of control chow or PLX5622 containing chow. b WT animals as well as APP-PS1 animals treated with PLX5622 showed a reduction of microglia cells $\left(\mathrm{Iba} 1^{+}\right.$and TMEM119 ${ }^{+}$) in the hippocampus compared to the respective control groups. Dapi was used as nucleus stain. Scale: $50 \mu \mathrm{m}$ (b) 
TMEM119, CD33 and Aif1 (=Iba1) were significantly downregulated after PLX5622 treatment in WT and APPPS1 animals (Fig. 5, Tables 2 and 3) confirming the microglia ablation at the transcriptome level. Most interestingly in the context of the present study, microglia ablation affected a variety of genes related to LT signaling in WT (Fig. 5a) and APP-PS1 mice (Fig. 5b). Indeed, the majority of LT-related genes were less expressed upon microglia depletion. For example, expression of the Alox5ap gene (= FLAP, on protein level) was significantly lower in the microglia depleted brains of WT as well as APP-PS1 animals. The genes Lta4h and Ltc4s, both enzymes involved in further metabolizing $\mathrm{LTA}_{4}$ (see Fig. 1), were not differentially expressed upon microglia ablation. However, Cysltr1, the gene for the Cys-LT receptor 1, was significantly decreased upon microglia ablation in WT and APP-PS1 animals. The genes of the two other cysteinylLT receptors (Cysltr2, Gpr17) remained unchanged. Surprisingly, although 5-Lox was found predominantly in neurons, Alox5 ( $=5$-Lox, on protein level) mRNA expression was lower in the microglia ablated brains (Tables 2 and 3).

For validation of the RNA sequencing data we performed qPCR gene expression analysis of key components of the LT signaling pathway (Fig. 6a, b). Microglia ablation resulted in a significant decrease in mRNA levels of the gene Alox5 and Alox5ap in WT as well as in APP-PS1 animals (Fig. 6a). On the receptor level, the qPCR data confirmed reduced mRNA expression of
Cysltr1 but not Cysltr2 or GPR17 in the hippocampus of microglia depleted brains (Fig. 6b). Similar results were obtained in the cortex (Supplementary Figure 2). Additionally, in the cortex, $L t c 4 s$ was significantly decreased in APP-PS1 + PLX522 and strongly reduced in WT + PLX5622 animals (Supplementary Figure 2A). In summary, microglia depletion not only diminished expression of Alox5ap, Ltc4s (in the cortex) and the receptor Cysltr1, but also expression of the Alox5 gene, which was surprising as the latter is predominantly expressed in neurons.

\section{FLAP is specifically expressed in microglia cells and abolished upon microglia ablation}

To further support the microglia specific expression of FLAP, its expression in the hippocampus in WT and APP-PS1 mice, and its response to the microglia depletion, we performed detailed immunohistochemical analysis (Fig. 7) in the brains of WT and APP-PS1 mice. Overall, in the hippocampus FLAP immunoreactivity was highest in APP-PS1 mice compared to WT and drastically reduced upon microglia ablation in WT and APP-PS1 mice (Fig. 7a). FLAP immunoreactivity was found in Iba1 positive microglia in WT and APP-PS1 mice (Fig. 7b, arrow), similarly to human FLAP staining that showed immunoreactivity in cells with glial morphology (Fig. 2b). Amyloid plaque associated microglia showed detectable but low FLAP immunoreactivity (Fig. $7 \mathrm{~b}$, red asterisk), while plaque-distant microglia were
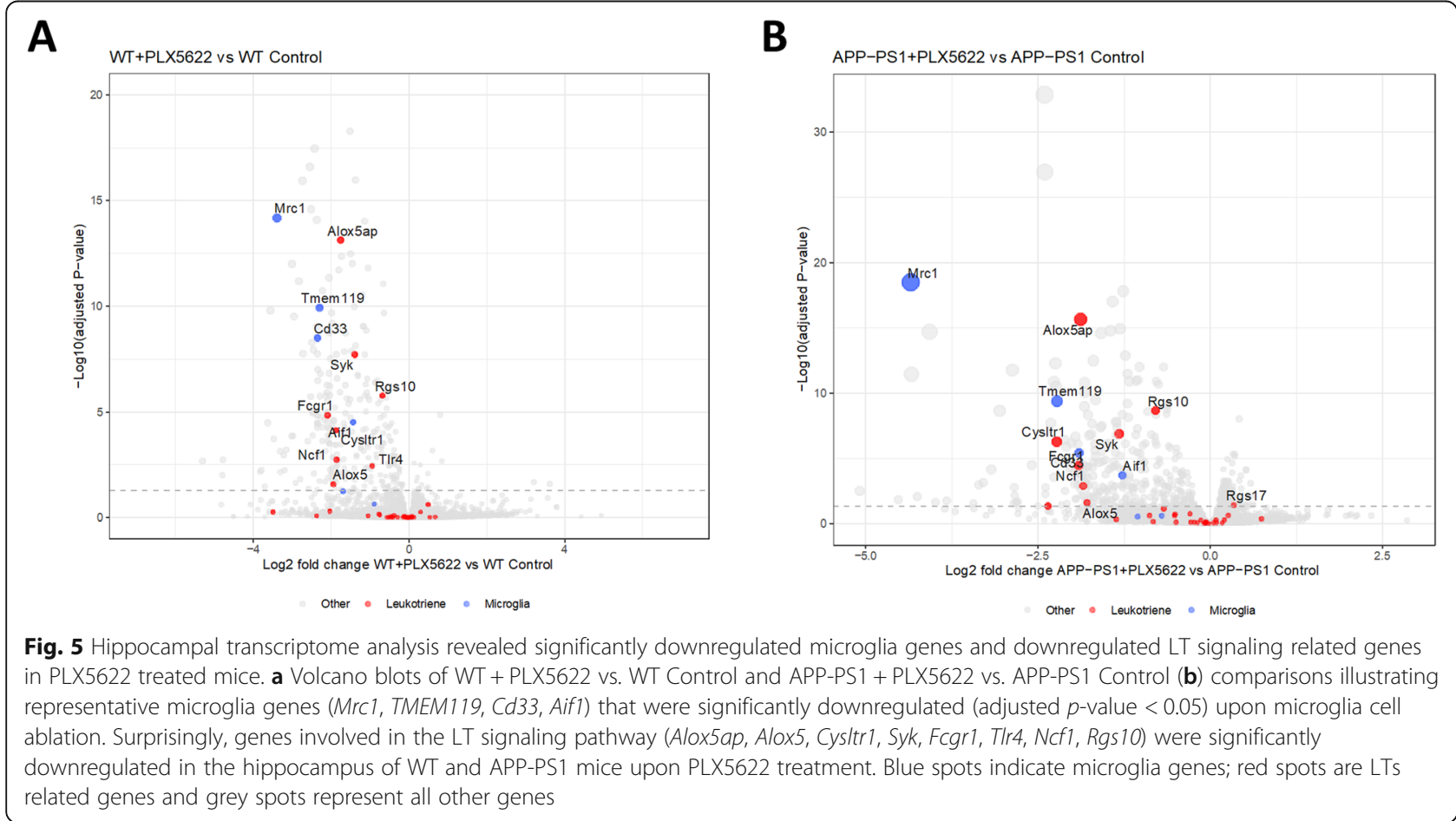

Fig. 5 Hippocampal transcriptome analysis revealed significantly downregulated microglia genes and downregulated LT signaling related genes in PLX5622 treated mice. a Volcano blots of WT + PLX5622 vs. WT Control and APP-PS1 + PLX5622 vs. APP-PS1 Control (b) comparisons illustrating representative microglia genes (MrC1, TMEM119, Cd33, Aif1) that were significantly downregulated (adjusted p-value < 0.05) upon microglia cell ablation. Surprisingly, genes involved in the LT signaling pathway (Alox5ap, Alox5, Cysltr1, Syk, Fcgr1, Tlr4, Ncf1, Rgs 10) were significantly downregulated in the hippocampus of WT and APP-PS1 mice upon PLX5622 treatment. Blue spots indicate microglia genes; red spots are LTs related genes and grey spots represent all other genes 
Table 2 List of differentially expressed genes in the hippocampus of WT + PLX5622 vs. WT control animals: Representative microglia genes and genes involved in the LT signaling pathway were significantly downregulated in WT+ PLX5622 mice. Genes with a significant adjusted $p$-value $(p<0.05)$ are presented in bold

\begin{tabular}{|c|c|c|c|}
\hline \multicolumn{4}{|c|}{ WT + PLX5622 vs. WT control } \\
\hline \multicolumn{4}{|c|}{ microglia genes } \\
\hline gene & gene description & $\begin{array}{l}\text { fold } \\
\text { change }\end{array}$ & $\begin{array}{l}\text { adjusted } \\
\text { p-value } \\
(p<0.05)\end{array}$ \\
\hline Mrc1 & mannose receptor, C type 1 & -3.38 & $6.93 \mathrm{E}-15$ \\
\hline Tmem119 & transmembrane protein 119 & -2.29 & $1.25 \mathrm{E}-10$ \\
\hline Trem2 & $\begin{array}{l}\text { triggering receptor expressed on } \\
\text { myeloid cells } 2\end{array}$ & -1.68 & $5.83 \mathrm{E}-02$ \\
\hline Cd68 & CD68 antigen & -0.88 & $2.38 \mathrm{E}-01$ \\
\hline$C d 33$ & CD33 antigen & -2.35 & $3.26 \mathrm{E}-09$ \\
\hline Aif1 & allograft inflammatory factor 1 & -1.42 & $3.20 \mathrm{E}-05$ \\
\hline \multicolumn{4}{|c|}{ leukotrienes signaling pathway } \\
\hline gene & gene description & $\begin{array}{l}\text { fold } \\
\text { change }\end{array}$ & $\begin{array}{l}\text { adjusted } \\
\text { p-value } \\
(p<0.05)\end{array}$ \\
\hline Alox5ap & $\begin{array}{l}\text { arachidonate } 5 \text {-lipoxygenase } \\
\text { activating protein }\end{array}$ & -1.75 & 7.70E-14 \\
\hline Alox5 & arachidonate 5 -lipoxygenase & -1.94 & $2.68 \mathrm{E}-02$ \\
\hline Lta4h & leukotriene A4 hydrolase & -0.02 & $9.92 \mathrm{E}-01$ \\
\hline Ltc4s & leukotriene C4 synthase & -0.50 & $9.87 \mathrm{E}-01$ \\
\hline Cysltr1 & $\begin{array}{l}\text { cysteinyl leukotriene receptor } \\
1\end{array}$ & -1.87 & $7.59 \mathrm{E}-05$ \\
\hline Cysltr2 & cysteinyl leukotriene receptor 2 & -0.74 & 7.77E-01 \\
\hline Gpri7 & G protein-coupled receptor 17 & -0.12 & 9.07E-01 \\
\hline Syk & spleen tyrosine kinase & -1.39 & $1.98 \mathrm{E}-08$ \\
\hline Fcgr1 & Fc receptor, IgG, high affinity I & -2.08 & $1.48 \mathrm{E}-05$ \\
\hline Tlr4 & toll-like receptor 4 & -0.94 & $3.78 \mathrm{E}-03$ \\
\hline Ncf1 & neutrophil cytosolic factor 1 & -1.85 & $1.92 \mathrm{E}-03$ \\
\hline $\operatorname{Rgs} 10$ & $\begin{array}{l}\text { regulator of G-protein signal- } \\
\text { ling } 10\end{array}$ & -0.67 & $1.75 \mathrm{E}-06$ \\
\hline Rgs17 & $\begin{array}{l}\text { regulator of G-protein signaling } \\
17\end{array}$ & -0.10 & $9.48 \mathrm{E}-01$ \\
\hline
\end{tabular}

strongly FLAP positive (Fig. 7b). FLAP and Iba1 staining were highly diminished in the PLX5622 treated WT and APP-PS1 mice compared to control groups. FLAP was still expressed in treatment resistant Iba1 positive cells. Similar findings were observed in the cortex (Supplementary Figure 3).

Increased numbers of 5-Lox ${ }^{+}$microglia in APP-PS1 mice and reduced 5-Lox immunoreactivity after microglia ablation in WT mice

Next, we analyzed the consequences of microglia ablation on 5-Lox expressing microglia and on overall 5-Lox
Table 3 List of differentially expressed genes in the hippocampus of APPPS1 + PLX5622 vs. APP-PS1 control animals: Representative microglia genes and genes involved in the LT signaling pathway were significantly downregulated in APPPS1 + PLX5622 mice. Genes with a significant adjusted $p$-value $(p<0.05)$ are presented in bold APP-PS1 + PLX5622 vs. APP-PS1 control

microglia genes

\begin{tabular}{|c|c|c|c|}
\hline gene & gene description & $\begin{array}{l}\text { fold } \\
\text { change }\end{array}$ & $\begin{array}{l}\text { adjusted } \\
\text { p-value } \\
(p<0.05)\end{array}$ \\
\hline Mrc1 & mannose receptor, C type 1 & -4.34 & $3.51 \mathrm{E}-19$ \\
\hline Tmem 119 & transmembrane protein 119 & -2.22 & 4.47E-10 \\
\hline Trem2 & $\begin{array}{l}\text { triggering receptor expressed on } \\
\text { myeloid cells } 2\end{array}$ & -1.05 & $3.26 \mathrm{E}-01$ \\
\hline Cd68 & CD68 antigen & -0.70 & $2.86 \mathrm{E}-01$ \\
\hline$C d 33$ & CD33 antigen & -1.90 & 4.04E-06 \\
\hline Aif1 & allograft inflammatory factor 1 & -1.27 & $2.12 \mathrm{E}-04$ \\
\hline \multicolumn{4}{|c|}{ leukotrienes signaling pathway } \\
\hline gene & gene description & $\begin{array}{l}\text { fold } \\
\text { change }\end{array}$ & $\begin{array}{l}\text { adjusted } \\
\mathrm{p} \text {-value } \\
(\mathrm{p}<0.05)\end{array}$ \\
\hline Alox5ap & $\begin{array}{l}\text { arachidonate } 5 \text {-lipoxygenase } \\
\text { activating protein }\end{array}$ & -1.78 & 2.81E-02 \\
\hline Alox5 & arachidonate 5 -lipoxygenase & -1.88 & $2.44 \mathrm{E}-16$ \\
\hline Lta4h & leukotriene A4 hydrolase & 0.09 & $5.62 \mathrm{E}-01$ \\
\hline$L t c 4 s$ & leukotriene C4 synthase & -1.36 & 5.05E-01 \\
\hline Cysltr1 & $\begin{array}{l}\text { cysteinyl leukotriene receptor } \\
1\end{array}$ & -2.23 & $5.48 \mathrm{E}-07$ \\
\hline Cysltr2 & cysteinyl leukotriene receptor 2 & 0.75 & 4.50E-01 \\
\hline Gpr17 & G protein-coupled receptor 17 & -0.13 & $6.06 \mathrm{E}-01$ \\
\hline Syk & spleen tyrosine kinase & -1.32 & $1.44 \mathrm{E}-07$ \\
\hline Fcgr1 & Fc receptor, IgG, high affinity I & -1.91 & 3.87E-05 \\
\hline T/r4 & toll-like receptor 4 & -0.67 & 7.90E-02 \\
\hline Ncf1 & neutrophil cytosolic factor 1 & -1.84 & $1.41 \mathrm{E}-03$ \\
\hline $\operatorname{Rgs} 10$ & $\begin{array}{l}\text { regulator of G-protein signal- } \\
\text { ling } 10\end{array}$ & -0.79 & 2.37E-09 \\
\hline Rgs17 & $\begin{array}{l}\text { regulator of G-protein signal- } \\
\text { ing } 17\end{array}$ & 0.34 & 4.33E-02 \\
\hline
\end{tabular}

immunoreactivity in the hippocampus (Fig. 8) and/or cortex (Supplementary Figure 4). We first quantified the percentage of 5 -Lox ${ }^{+}$cells in the $\mathrm{Iba}^{+}$cell population in the hippocampus of all experimental groups (Fig. 8a, b). In WT animals the percentage of 5 - $\mathrm{Lox}^{+} / \mathrm{Iba}^{+}$cells was low, but in APP-PS1 mice significantly more $\mathrm{Iba}^{+}$cells expressed 5-Lox (20-30\%). Microglia depletion with PLX5622 did not change the percentage of $5-\mathrm{Lox}^{+} / \mathrm{Iba}^{+}$ cells in WT mice but reduced numbers of microglia expressing 5-Lox were detected in APP-PS1 animals (Fig. $8 b)$. This data suggests that microglia react with increased numbers of 5 - $\mathrm{Lox}^{+} / \mathrm{Ibal}^{+}$cells to a chronic 


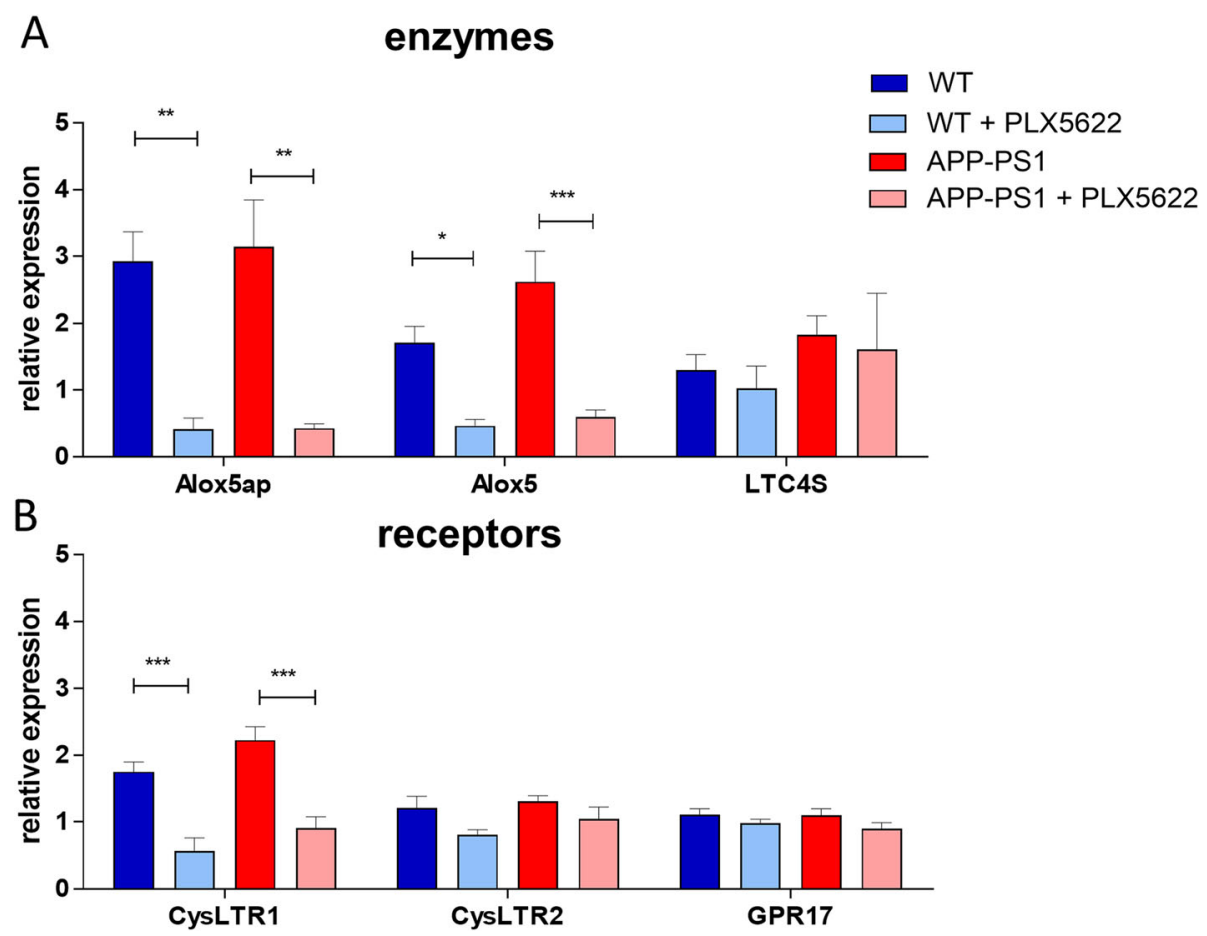

Fig. 6 qPCR validation of hippocampal mRNA expression for LT synthesis related genes: a Microglia ablation in WT and APP-PS1 mice resulted in significantly lower mRNA expression of Alox5ap and Alox5. b Expression of cysteinyl-LT receptor CysLTR1 was significantly decreased upon microglia ablation in WT and APP-PS1 mice. One-way analysis of variance with Bonferroni's multiple comparison test was used. $P$-values $<0.05$ were considered significant. Data are shown as mean with SEM

inflammatory environment in the APP-PS1 mice. After microglia ablation in APP-PS1 mice, remaining microglia still express 5 -Lox, however in a more physiological role comparable to WT animals.

Most interestingly, we observed that upon PLX5622 treatment the overall immunoreactivity of neuronal 5Lox expression in the granular layer was remarkably reduced in some animals (Fig. 8, Supplementary Figure 5 and Supplementary Figure 7). To verify this observation, we analyzed the percentage of overall 5-Lox staining in the hippocampus (Fig. 8a, c). We observed significantly increased 5-Lox staining (\% area) in the hippocampus of APP-PS1 mice compared to WT animals and very surprisingly the percentage of 5-Lox staining was reduced in microglia depleted WT but not in APP-PS1 mice (Fig. 8c). However, within APP-PS1 + PLX5622 mice, a huge inter-individual variation of 5-Lox expression was observed. Significantly reduced 5-Lox expression was particularly seen in in WT + PLX5622 mice. This might indicate a potential feedback and neuronal response to the lack of physiological microglia cell numbers. Similar findings were observed in the cortex (Supplementary Figure 4).

To further confirm reduced neuronal 5-Lox immunoreactivity, we repeated the staining for 5-Lox i) using the exact same monoclonal antibody as used on the human brain specimen (Supplementary Figure 5 and Supplementary Figure 6) and ii) comparing the result also with a polyclonal 5-Lox antibody from rabbit species (Supplementary Figure 7 and Supplementary Figure 8) (for summary of used antibodies see Table 1). Whereas the mouse monoclonal antibody detected 5-Lox only in neurons, the poly- and monoclonal rabbit antibodies detected 5-Lox also in mouse microglia cells. Upon microglia ablation 5-Lox immunoreactivity, as detected by all three different antibodies, was remarkably diminished in the neurons of the dentate gyrus especially from WT + PLX5622 animals.

Visualization of 5-Lox expressing cells in a WT mouse section in high magnification and 3D rendering (Fig. 9) illustrates that 5-Lox is localized in the nucleus of mature neurons but also in a nuclear and perinuclear pattern in some microglia cells (Fig. 9, arrow), see also Video file 1. A huge body of evidence by now indicates that the nuclear envelope is a significant production site of LTs, and that 5-Lox can be found at the nuclear membrane and close to it on both sides of the nuclear membrane (reviewed in [56]; and [57]). Also suggested by the literature [56] the nuclear membrane location of 5-Lox most likely represents an activated form of the 5Lox enzyme further supporting that microglia might be a production site of LTs, as we find 5-Lox located 

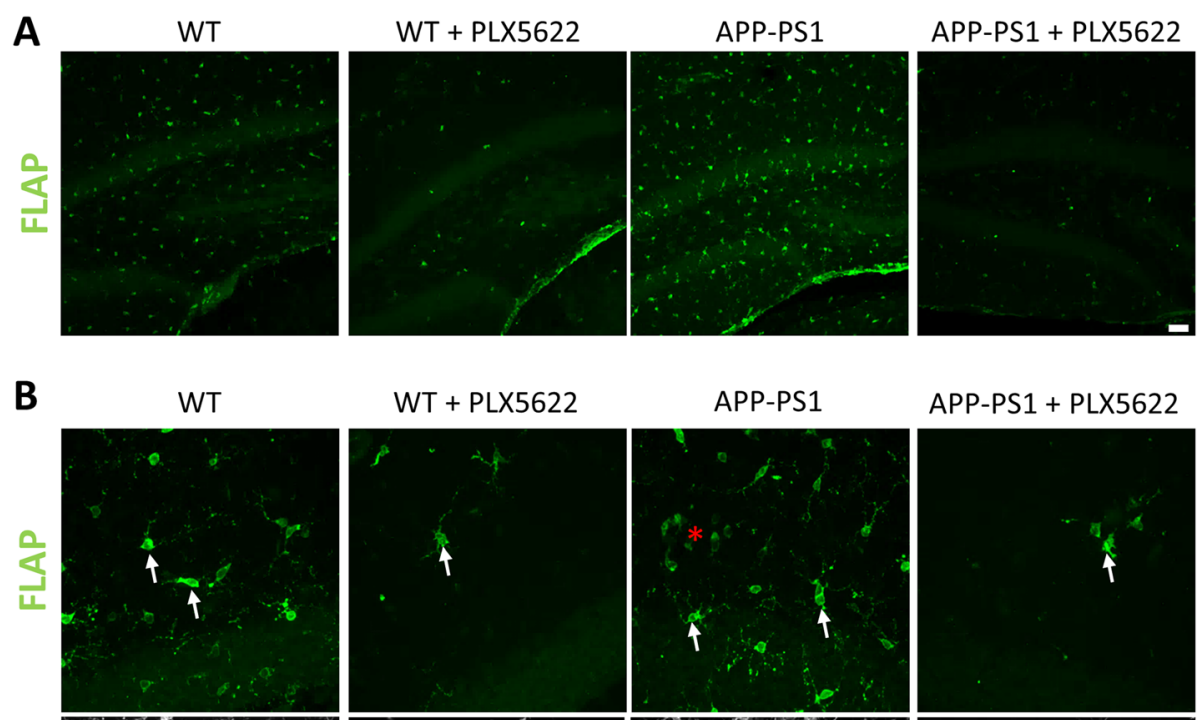

APP-PS1 + PLX5622
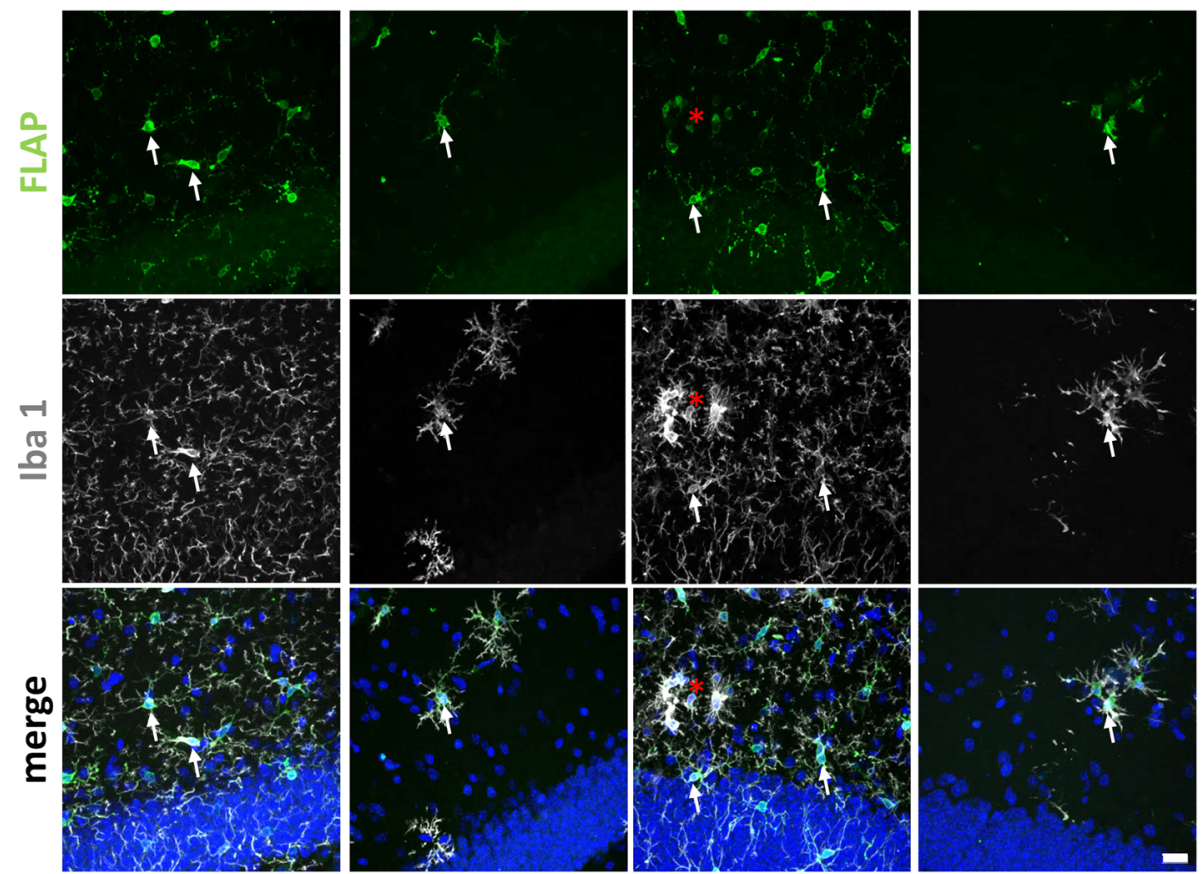

Fig. 7 Immunohistochemical analysis of FLAP expression in the hippocampus. a Overall FLAP (green, polyclonal FLAP antibody from Novus Biologicals NBP1-84666) expression was more prominent in APP-PS1 compared to WT control animals and highly reduced with PLX5622 treatment. b FLAP co-localized with Iba1 (white) positive cells in all groups (arrows). Most interestingly, the intensity of FLAP staining in microglia at sites of amyloid plaques was reduced (red asterisk). Dapi was used as nucleus stain. Scale: $50 \mu \mathrm{m}(\mathbf{a}), 20 \mu \mathrm{m}$ (b)

perinuclear in Iba1+ cells microglia are highly activated at sites of amyloid plaques, so in order to address where FLAP and 5-Lox are expressed intracellular, we performed co-staining of 5-Lox with FLAP in APP-PS1 mice and performed $3 \mathrm{D}$ reconstruction of the confocal images (Fig. 10). We observed co-localization of both proteins at sites of the nuclear membrane in cells associated with the amyloid plaque (Fig. 10).

We conclude from this data that FLAP is predominantly expressed by microglia cells, whereas 5-Lox is mainly expressed by neurons and only expressed by a subpopulation of microglia cells. Nevertheless, as FLAP and 5-Lox need to be physically present in the same cell, we assume that microglia are the main source for Leukotrienes in the brain. Furthermore, this illustrates that microglia depletion leads also to a down-regulation of 5Lox expression in neurons suggesting that the absence of microglia might modulate 5-Lox expression in neurons under healthy conditions. However, to verify this hypothesis and to investigate the contribution of chronic inflammation on neuronal 5-Lox expression further experiments have to be performed in the future.

\section{Discussion}

In the present study we show that FLAP, a key activator molecule of the LT biosynthesis pathway, is expressed in all microglia and not in any other cell type of the brain. 5-Lox is present in a microglia subpopulation, in particular in the context of AD pathology. The most predominant expression of 5-Lox, however, is present in neurons. Microglia ablation drastically reduced the expression of microglia associated LT pathway components such as FLAP and Cysltr1. In addition, and surprisingly, also neuronal 5-Lox expression was 

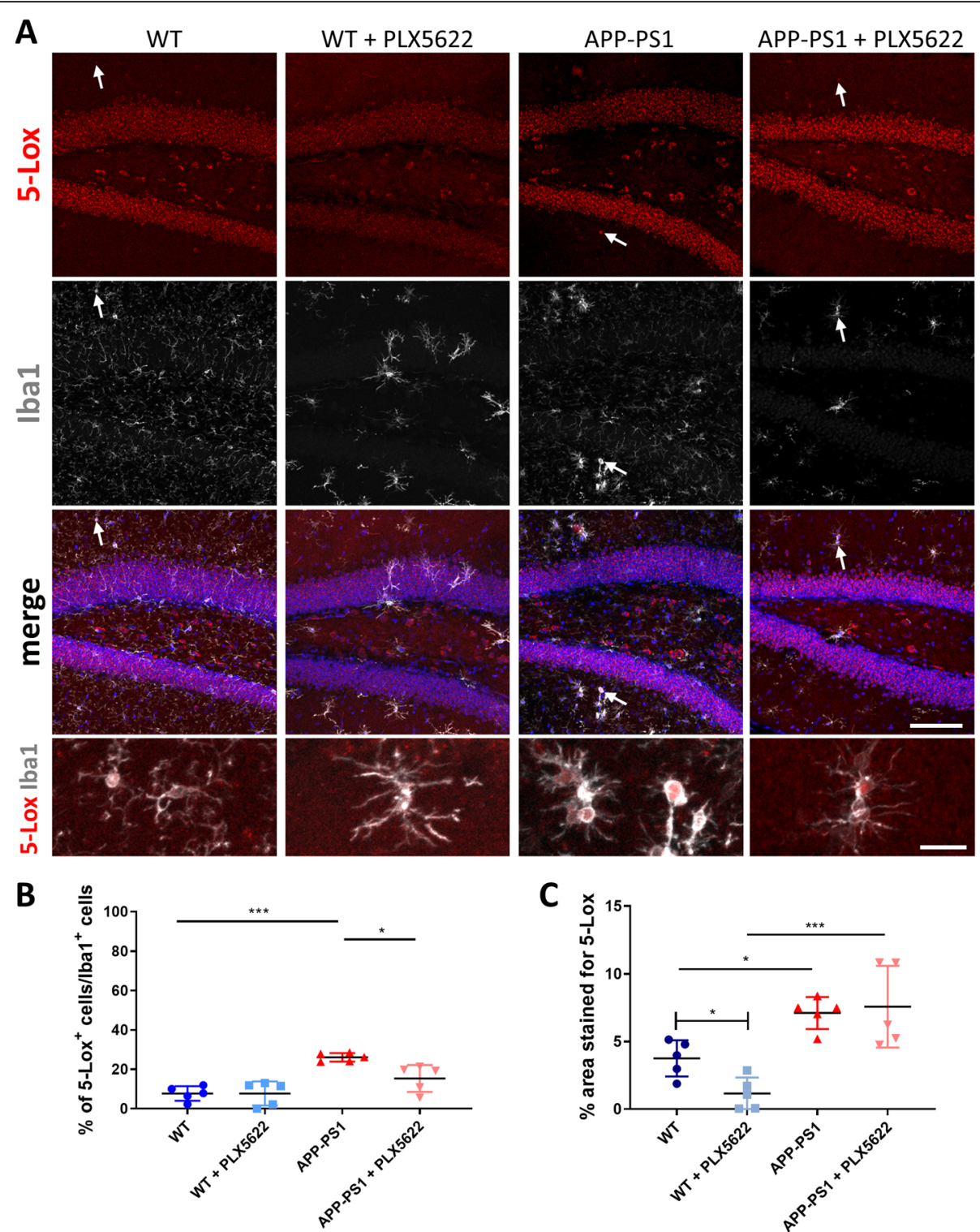

Fig. 8 Immunohistochemical analysis of 5-Lox expression in the hippocampus. a 5-Lox (red, monoclonal 5-Lox antibody from Abcam \#ab169755) was primarily expressed in neurons of the granular cell layer but did also co-localize with some lba1 (white) positive cells (arrow or inserts). $\mathbf{b}$ We analyzed the percentage (\%) of 5-Lox ${ }^{+}$cells in the $\mathrm{Iba}^{+}{ }^{+}$cell population revealing increased numbers of 5-Lox + microglia in APP-PS1 mice compared to WT animals. 5-Lox ${ }^{+}$microglia numbers were reduced in APP-PS1 + PLX5622 animals. c The overall 5-Lox staining (\% area stained by 5-Lox) was increased in APP-PS1 mice compared to WT animals and reduced upon microglia depletion in WT + PLX5622 mice. Remaining microglia in PLX5622 treated mice displayed altered cell morphology. One-way analysis of variance with Tukey's multiple comparison test (b, c) and unpaired t test comparing WT vs. WT + PLX5622 (c) was used. P-values $<0.05$ were considered significant. Data are shown as mean with SD. Dapi was used as nucleus stain. Scale: $100 \mu \mathrm{m}$ and $20 \mu \mathrm{m}$ inserts (a)

diminished after microglia depletion, especially in WT mice. The function of 5-Lox in neurons is unclear, but the absence of FLAP in neurons points towards a 5-Lox function, which might not directly relate to LT synthesis. Nevertheless, microglia clearly influenced 5-Lox expression in neurons, which seemed to depend on the presence of microglia, especially under non-disease conditions. Thus, 5-Lox expression might serve as indicator for the neuroinflammatory stress load in neurons [58].
Alternatively, 5-Lox together with 12-Lox and 15-Lox is also important for the formation of so-called specialized pro-resolving mediators (SPMs), which are antiinflammatory and pro-resolving lipid mediators that actively promote homeostasis during inflammation [59-61]. A reduction in neuronal 5-Lox following microglia ablation could therefore also be a sign for lesser need of anti-inflammatory stimuli due to a lower numbers of proinflammatory signals from microglia. However, the 


\section{NeuN 5-Lox Iba1 (all 3D)}

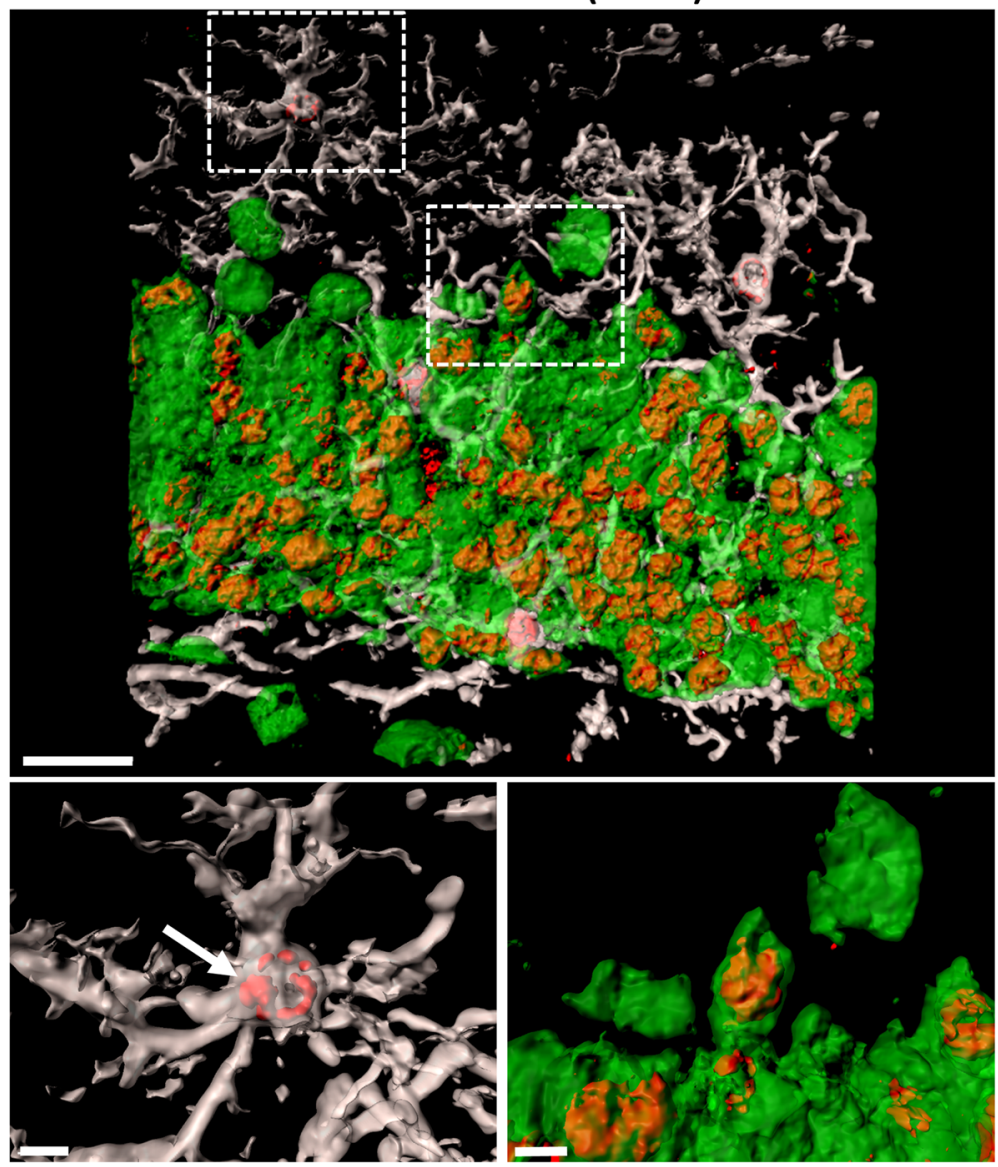

Fig. 9 3D Render of images with Imaris Software. 5-Lox immunoreactivity (red, using polyclonal 5-Lox antibody from Abcam \#ab39347) is shown in NeuN positive neurons (green) of the granular cell layer in the dentate gyrus and in some lba1 positive microglia cells (white). In microglia cells 5-Lox staining clustered at the nuclear membrane indicating an activated form of the 5-Lox enzyme (arrow). Scale: $20 \mu \mathrm{m}$ and $5 \mu \mathrm{m}$ inserts

explicit function or functions of 5-Lox in neurons are still elusive and need further investigations.

FLAP is widely expressed in peripheral organs, in particular associated with infiltrating leukocytes, such as in lung [62] and muscle tissue [63]. In the brain, we observed FLAP exclusively expressed in all microglia cells. Interestingly in this context, we did observe a more intense FLAP immunoreactivity in APP-PS1 mice, probably due to an increased number of microglia cells. This presents FLAP as a potential candidate for a novel microglia marker. On the gene expression level, this is supported by a recent study demonstrating that in the brain Alox5ap mRNA expression is microglia-specific as well as significantly differently expressed in AD transgenic mice (TASTPM model) versus WT controls [64]. Furthermore, in these $\mathrm{AD}$ mice Alox5ap expression in microglia was age-dependent and highest in the hippocampus and the cortex. In human AD brains Alox5ap expression was especially high in microglia of the temporal cortex as well as in the superior temporal gyrus
[64]. This illustrates that FLAP expression underlies dynamic changes along age, brain region and disease status. Indeed, microglia are highly heterogeneous in the healthy [65] as well as in the diseased brain [66]. They exist in several most likely overlapping subpopulations as for example disease associated microglia (DAM) [67], Lipid-droplet-accumulating microglia (LDAM) [68] and $\mathrm{AD}$-associated microglia [69]. We made use of publically available gene expression databases for these microglia subpopulations and analyzed for 5-Lox and FLAP expression, respectively the Alox5 and Alox5ap genes. ADassociated microglia have reduced levels of Alox5ap as well as Alox5 RNA compared to WT microglia [69]. Also, in DAMs Alox5ap mRNA expression is lower compared to homeostatic microglia [67]. However, LDAM microglia were not associated with altered Alox5 or Alox5ap levels [68]. Here, we show that plaque associated microglia in APP-PS1 mice have reduced FLAP immunoreactivity suggesting that such FLAP low and plaque associated microglia might be DAMs and/or AD- 


\section{DAPI FLAP (3D) 5-Lox (3D)}
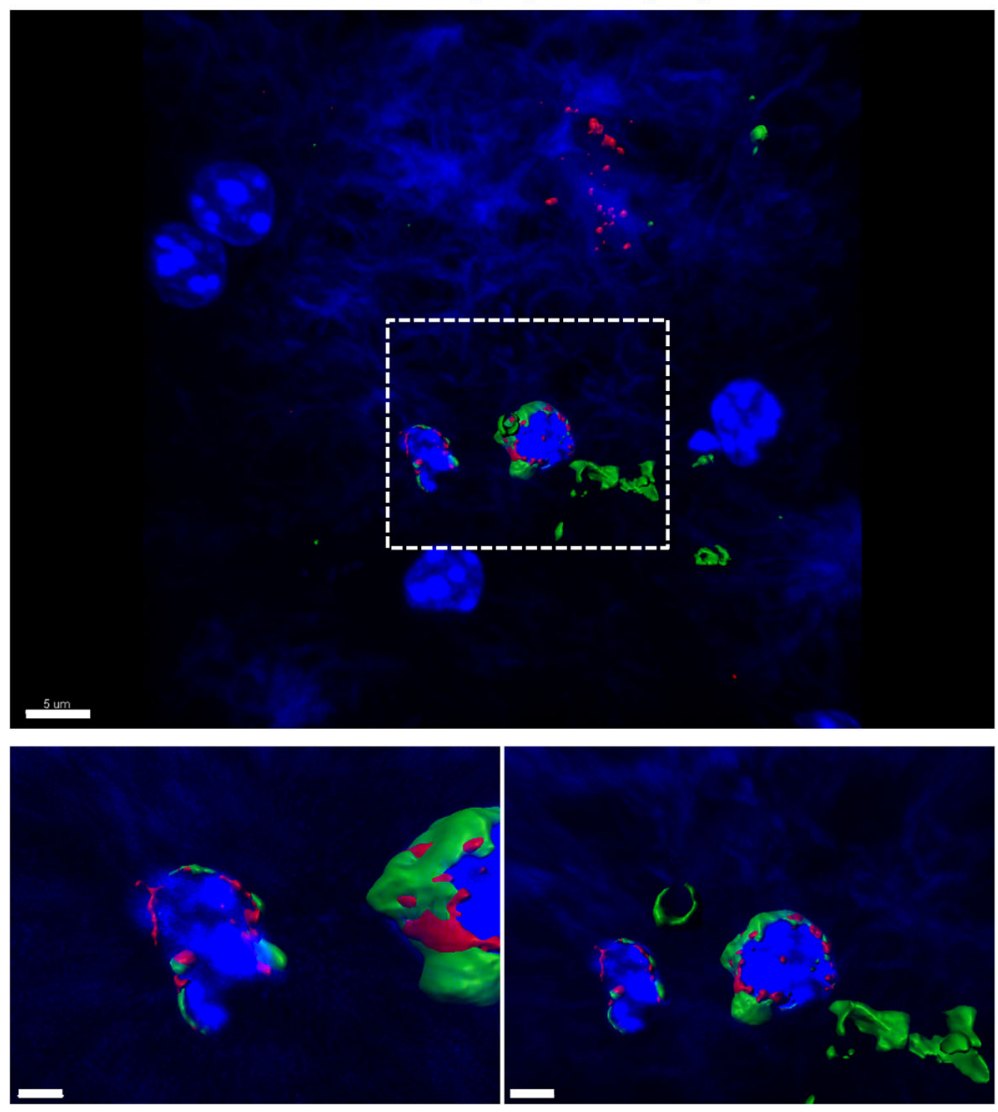

Fig. 10 3D Render of images with Imaris Software. 5-Lox (red, using polyclonal 5-Lox antibody from Abcam \#ab39347) is expressed in FLAP (green, polyclonal FLAP antibody from Novus Biologicals NB300-891) positive cells associated with the amyloid plaque. 5-Lox and FLAP are in close contact at sites of the nuclear membrane. Dapi was used as nucleus stain. Scale: $5 \mu \mathrm{m}, 1 \mu \mathrm{m}$ (insert left), $2 \mu \mathrm{m}$ (insert right)

associated microglia. Therefore, FLAP intensity could be used as marker to further stratify microglia subpopulations and to characterize microglia phenotypes or activation state. This, however, requires further detailed investigations in future.

The cell-type specific expression of 5-Lox and FLAP in the brain has so far been investigated at the mRNA level by in situ hybridization of rat brains in one other study concluding that 5-Lox and FLAP are expressed in neurons [30]. In the present study, we observed FLAP expression specifically in microglia and not in neurons, using two different commercially available FLAP antibodies. 5-Lox staining was present in neurons and limited to a microglia subpopulation. Obviously, the clear identity of the latter requires further investigation. As our results are only partially in line with the above mentioned study from 1996 [30], which indicated neuronspecific expression of 5-Lox and FLAP, we intensively researched microglial and neuronal expression of Alox5ap and Alox5 in publically available databases. First, microglia isolated from mouse cerebral cortex express roughly 27 times more Alox5ap (FPKM: 321.5) than Alox5 (FPKM: 12.3) (following FPKM values taken from: http://www.brainrnaseq.org/ [70, 71], suggesting that in microglia FLAP is higher expressed compared to 5-Lox. The same is true for humans (microglia Alox5ap (FPKM 140.5), Alox5 (FPKM 5.9)). Second, in mouse neurons, expression of Alox5ap (FPKM 0.8) and of Alox5 (FPKM 0.1) is very low and also in human neurons Alox5ap (FPKM 2.0) and Alox5 (FPKM 0.1) are expressed at a very low level (data derive from non-disease and young conditions). Third, Alox5 in mouse microglia (FPKM 12.3) was higher expressed compared to neurons (FPKM 0.1). Similarly, this is the case in humans (Alox5: in microglia FPKM 5.9, in neurons FPKM 0.1). Forth, in mice Alox5ap was higher expressed in microglia (FPKM 321.5) compared to neurons (FPKM 0.8). The same was true in humans (Alox5ap: in microglia FPKM 140.5, in neurons FPKM 2.0. This is mostly in line with our histological data from mouse hippocampus and cortex where we show wide expression of FLAP in microglia, 


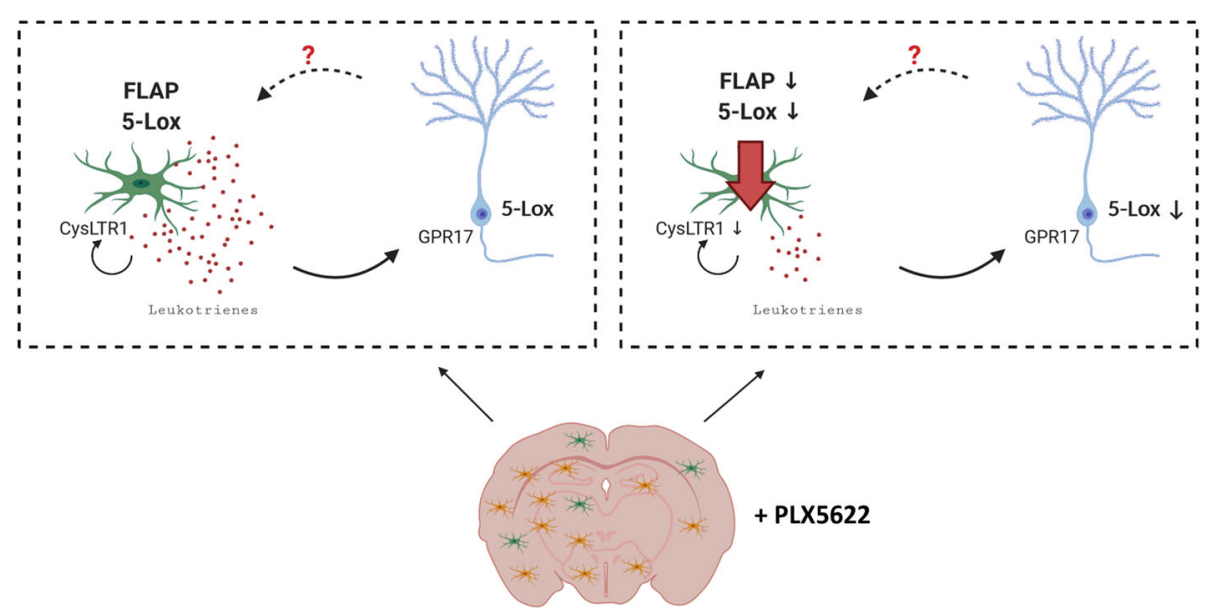

Fig. 11 Hypothetical model for microglia as source of LTs in the brain. Key elements of the LTs synthesis pathway are FLAP and 5-Lox, which are co-expressed in some microglia cells (green). Additionally, 5-Lox staining was observed in neurons (blue). It is known that 5-Lox and FLAP protein need to form an intracellular complex to start the synthesis pathway resulting in the production of LTs (left panel). With the herein shown microglia ablation experiment (+PLX5622), we could confirm microglia cells as potential source for LTs. In microglia ablated brains (right panel) FLAP and 5-Lox expression as well as CysLTR1 was highly decreased. Additionally, our data supports the idea of a putative microglia neuron interaction, as 5-Lox immunoreactivity was reduced in neurons of microglia ablated WT brains. LTs thereby possibly affect microglia in an autocrine manner via the CysLTR1, and neurons via GPR17. We hypothesize a putative feedback loop between neurons and microglia involving LTs signaling in the context of neuroinflammation. Image was created with BioRender.com

but only a smaller proportion of microglia express 5 Lox. We observed 5-Lox immunoreactivity predominantly in neurons and moderate levels of Alox5 in the hippocampus and cortex, although we investigated already aged and diseased animals. Therefore, the comparison with the above-mentioned database is limited and has to be carefully interpreted as data derive from young and healthy animals.

5-Lox and FLAP are the initiators of LTs synthesis $[72,73]$ and need to be in close proximity within a cell [22]. Thus, we expected a high level of coexpression between 5-Lox and FLAP, as it was previously shown in mast cells for example by single molecule localization microscopy [74]. Apparently, only a subpopulation of microglia co-express 5-Lox and FLAP. A vast majority of 5-Lox is found in neurons. If this neuronal 5-Lox might contribute to LT synthesis is unclear, but since 5-Lox activity requires FLAP for its membrane anchoring and activation, it is unlikely that neuronal 5-Lox contributes to LT synthesis. 5-Lox immunoreactivity has been demonstrated in neurons, and also in astrocytes and microglia after MCAO in rats [75]. Furthermore, increased neuronal 5-Lox staining was also reported in $\mathrm{AD}$ patients, showing 5-Lox in the granular layer of the dentate gyrus and CA1-3 regions [1]. The latter paper was drawing also the attention to the fact that different 5Lox antibodies might show different results, i.e. different glial or non-glial cell 5-Lox immunoreactivity [1]. In the present work we approached the topic on antibody specificity by using three commercially available and different 5-Lox antibodies (Abcam and BD Biosciences) from different hosts (mouse and rabbit) targeting different epitopes, i.e. either the $\mathrm{C}$ - or $\mathrm{N}$ terminal sites, of the 5-Lox molecule. Consistently, all three antibodies detected 5-Lox primarily always in neurons, two of the antibodies detected 5-Lox also in microglia (see Table 1).

A possible way of 5-Lox distribution in the CNS could be extracellular vesicles (EVs) and their intercellular exchange might explain the presence of 5-Lox in various CNS cell types. EVs include not only various proteins and mRNA but also nucleic acids and lipids (reviewed in [76]). Furthermore, EVs are described to carry eicosanoids which can be shuttled together with an enzyme machinery for eicosanoid production (reviewed in [77]). For example, EVs from human macrophages and dendritic cells in the context of lung inflammation and/or asthma were shown to comprise FLAP and 5-Lox as well as other components of the LTs biosynthesis pathway [78]. However, if this is also true in the healthy or diseased brain and if microglia and neuron can shuttle 5Lox via exosomes as response to inflammatory stimuli is at this point pure speculation. Thus, considering the present data and concluding from the available literature, the majority of 5-Lox immunoreactivity is confined to neurons and to a lesser extend it is expressed in some microglia cells. Single cell transcriptome profiling of neurodegenerative brains will certainly be required to further underscore our findings. 


\section{Conclusion}

We conclude that FLAP and 5-Lox co-expression identifies a microglia subpopulation which is the presumed cellular source of LTs in the brain and which is more prominent in the context of AD. FLAP is expressed exclusively and by all microglia in the brain presenting it as a possible novel microglial marker. The majority of 5-Lox is found in neurons and is elevated in neurodegeneration. As neurons do not show detectable FLAP, it is unlikely that they produce LTs unless they have a FLAP-like mechanism to anchor 5-Lox to membranes. Neuronal 5-Lox expression strongly depends on the presence of microglia suggesting the presence of a feedback signal between neurons and microglia. It might be a first response to inflammatory and/or degenerative conditions. LTs might either in an autocrine or paracrine manner stimulate microglia via CysLTR1 [6], which has been localized on microglia, but also signal to neurons via GPR17, a LT receptor predominantly expressed on neurons [79] (Fig. 11). Our herein shown data deliver new insights in the cellular components involved in LT synthesis in the brain, with strong focus on microglia. This data might improve knowledge on the use of already existing anti-LT drugs in diseases of the CNS.

\section{Supplementary information}

Supplementary information accompanies this paper at https://doi.org/10. 1186/s40478-020-00989-4.

Additional file 1: Supplementary Figure 1. Immunohistochemistry for Iba1 and TMEM119 in cortical brain regions. Microglia (Iba $1^{+}$and TMEM119 ${ }^{+}$) were ablated in WT and APP-PS1 mice using PLX5622. Dapi was used as nucleus stain. Scale: $50 \mu \mathrm{m}$.

Additional file 2: Supplementary Figure 2. qPCR of cortical mRNA expression for LT synthesis related genes: (A) Microglia ablation in WT and APP-PS1 mice resulted in significant decline of Alox5ap mRNA. Alox5 and LTC4S mRNA expression was significantly decreased after microglia ablation in APP-PS1 animals and reduced in WT mice. (B) Relative mRNA expression of cysteinyl-LT receptor CysLTR1 was significantly decreased upon microglia ablation in WT and APP-PS1 mice. One-way analysis of variance with Bonferroni's multiple comparison test was used. P-values < 0.05 were considered significant. Data are shown as mean with SEM.

Additional file 3: Supplementary Figure 3. Analysis of FLAP expression in the cortex. (A) Overall FLAP (green) expression was more prominent in APP-PS1 compared to WT control animals and highly reduced with PLX5622 treatment. (B) FLAP co-localized with Iba1 (white) positive cells in all groups (arrows). Most interestingly, the intensity of FLAP staining in microglia at sites of amyloid plaques was reduced (red asterisk). Dapi was used as nucleus stain. Scale: $50 \mu \mathrm{m}$ (A), $20 \mu \mathrm{m}$ (B).

Additional file 4: Supplementary Figure 4. Immunohistochemical analysis of 5-Lox expression in the cortex. We verified 5-Lox immunostaining in neurons and microglia cells using a monoclonal 5-Lox antibody. 5Lox (red, monoclonal 5-Lox antibody from Abcam \#ab169755) was primarily expressed in neurons but did also co-localize with some Iba1 (white) positive cells (arrows and inserts). Most interestingly, overall the 5Lox staining was reduced upon microglia ablation using CSF1R inhibitor PLX5622. Remaining microglia in PLX5622 treated mice displayed altered cell morphology. Dapi was used as nucleus stain. Scale: $20 \mu \mathrm{m}$ and $10 \mu \mathrm{m}$ inserts.
Additional file 5: Supplementary Figure 5. To confirm our data on the reduction of 5-Lox staining in the dentate gyrus after microglia ablation, we performed an additional staining with the mouse anti-5-Lox antibody (monoclonal 5-Lox antibody from BD Biosciences \#610694), the same used for human tissue. With this antibody 5-Lox immunoreactivity was exclusively found in neurons and did not co-localize with Iba1 positive cells in all groups (inserts). However, most interestingly the 5-Lox staining was again reduced in the granular layer of the dentate gyrus upon microglia ablation. Dapi was used as nucleus stain. Scale: $50 \mu \mathrm{m}$ and $20 \mu \mathrm{m}$ inserts.

Additional file 6: Supplementary Figure 6. To confirm our data on the reduction of 5-Lox staining in cortical neurons after microglia ablation, we performed an additional staining with the mouse anti-5-Lox antibody (monoclonal 5-Lox antibody from BD Biosciences \#610694), the same used for human tissue. With this antibody 5-Lox immunoreactivity was exclusively found in neurons and did not co-localize with Iba1 positive cells in all groups (inserts). However, most interestingly the 5-Lox staining was again reduced in neurons upon microglia ablation. Dapi was used as nucleus stain. Scale: $20 \mu \mathrm{m}$ (both).

Additional file 7: Supplementary Figure 7. Immunohistochemical analysis of 5-Lox expression in the hippocampus. 5-Lox (red, using polyclonal 5-Lox antibody from Abcam \#ab39347) was primarily expressed in neurons of the granular cell layer but did also co-localize with some Iba1 (white) positive cells (arrows and inserts). Most interestingly, overall the 5Lox staining in the granular layer was reduced upon microglia ablation using CSF1R inhibitor PLX5622. Remaining microglia in PLX5622 treated mice displayed altered cell morphology. Dapi was used as nucleus stain. Scale: 20 and $10 \mu \mathrm{m}$ inserts.

Additional file 8: Supplementary Figure 8. Immunohistochemical analysis of 5-Lox expression in the cortex. 5-Lox (red, using polyclonal 5Lox antibody from Abcam \#ab39347) was primarily expressed in neurons but did also co-localize with some lba1 (white) positive cells (inserts). Most interestingly, overall the 5-Lox staining was reduced upon microglia ablation using CSF1R inhibitor PLX5622. Dapi was used as nucleus stain. Scale: 50 and $20 \mu \mathrm{m}$ inserts.

Additional file 9: Supplementary Table 1. List of patients samples including neuropathological assessment of pathological diagnosis (Path Diag), NFT Braak, CERAD, NIA-RI, Thal Abeta, NIA-AA, Braak LB and McKeith stage scores as wells as age, gender and MMSE score information.

Additional file 10: Video file 1. 3D Render of 5-Lox expression in the hippocampus of WT mouse. 5-Lox in red, Iba1 in white and NeuN in green. Video was generated using Imaris software.

\section{Abbreviations}

5-Lox: 5-lipoxygenase; AA: Arachidonic acid; AD: Alzheimer's disease; AIF1: Allograft inflammatory factor 1; Alox5: Arachidonate 5-lipoxygenase (gene name); Alox5ap: Arachidonate 5-lipoxygenase activating protein (gene name); APPPS1: APP Swedish PS1 dE9; BBB: Blood-brain-barrier; CA1-3: Cornu Ammonis 1-3; CD33: Cluster of differentiation 33, sialic acid binding Ig-like lectin 3; CNS: Central nervous system; CSF1R: Colony stimulating factor 1; CysLT1R: Cysteinylleukotriene receptor 1; CysLT2R: Cysteinylleukotriene receptor 2; CysLTs: Cysteinylleukotrienes; DAM: Disease associated microglia; DHA: Docosahexaenoic acid; EPA: Eicosapentaenoic acid; EVs: Extracellular vesicles; FLAP: 5-lox activating protein; GPR17: G-protein coupled receptor 17; Iba1: Ionized calcium-binding adapter molecule 1; LAM: Lipid droplet associated microglia; LT: Leukotriene; LTA4: Leukotriene A 4; Lta4h: Leukotriene A 4 hydrolase; LTB4: Leukotriene B 4; LTC4S: Leukotriene C 4 synthase; Mrc1: Mannose receptor C-Type 1; NBTR: Newcastle brain tissue resource; NFT: Neurofibrillary tangles; SPM: Specialized pro-resolving mediator; TMEM119: Transmembrane protein 119; WT: Wild-type

\section{Acknowledgments}

The authors thank the microscopy core facility of SCI-TReCS (Spinal Cord Injury and Tissue Regeneration Center Salzburg). JM is supported through a fellowship from IntelGenx Corp. Furthermore, we thank Plexxikon Inc. and Research Diets Inc. for providing PLX5622 and AIN-76A chow. We thank Pia Zaunmair for her help with the animal breeding. 


\section{Authors' contributions}

JM performed histological analysis of human and mouse tissue, aPCR analysis and wrote the manuscript. MU planned and conducted the animal experiment, helped with immunohistochemistry and wrote the manuscript. RP performed all bioinformatics analyses of the RNAseq data. PS helped with the animal experiment and sample processing together with HM who helped with animal perfusion and GPCR. JA was involved in critical revision of the manuscript and additionally provided human post-mortem brain specimen. LA is the principle investigator and was involved in the experimental designs, in critical revision and drafting of the manuscript.

\section{Funding}

This work was supported by the FWF Special Research Program (SFB) F44 (F4413B23) "Cell Signaling in Chronic CNS Disorders", by the FWF Project P 31362-B34, the PMU-FFF A-15/01/017-MAR, and a PhD fellowship from IntelGenx corp. Funding bodies did not influence the design of the study and collection, analysis, interpretation of data, and writing of the manuscript.

\section{Availability of data and materials}

Authors declare availability of data and material upon request.

\section{Ethics approval and consent to participate}

Animal care, handling, genotyping and experiments were approved by local ethical committees (BMWFW-66.019/0011-WFN/3b/2016 and BMWFW66.019/0032-WF/N/3b/2016).

\section{Consent for publication}

Human patients data are anonymized and therefore, it is not applicable.

\section{Competing interests}

LA declares that he is consultant at IntelGenx corp., Canada, which has a clinical program for the development of Montelukast in AD. JM declares that she has received a PhD fellowship from IntelGenx corp. The authors declare that they have no competing interests.

\section{Author details}

${ }^{1}$ Institute of Molecular Regenerative Medicine, Paracelsus Medical University, Strubergasse 21, 5020 Salzburg, Austria. ${ }^{2}$ Spinal Cord Injury and Tissue Regeneration Center Salzburg (SCI-TReCS), Paracelsus Medical University, Salzburg, Austria. ${ }^{3}$ Experimental and Clinical Cell Therapy Institute, Paracelsus Medical University, Salzburg, Austria. ${ }^{4}$ Institute of Neuroscience, Newcastle University, Newcastle upon Tyne, UK. ${ }^{5}$ Austrian Cluster for Tissue Regeneration, Vienna, Austria.

Received: 3 July 2020 Accepted: 4 July 2020

Published online: 08 August 2020

\section{References}

1. Ikonomovic MD, Abrahamson EE, Uz T, Manev H, Dekosky ST (2008) Increased 5-lipoxygenase immunoreactivity in the hippocampus of patients with Alzheimer's disease. J Histochem Cytochem 56(12):1065-1073

2. Firuzi O, Zhuo J, Chinnici CM, Wisniewski T, Pratico D (2008) 5-Lipoxygenase gene disruption reduces amyloid-beta pathology in a mouse model of Alzheimer's disease. FASEB J 22(4):1169-1178

3. Farias SE, Zarini S, Precht T, Murphy RC, Heidenreich KA (2007) Transcellular biosynthesis of cysteinyl leukotrienes in rat neuronal and glial cells. J Neurochem 103(4):1310-1318

4. Farias S, Frey LC, Murphy RC, Heidenreich KA (2009) Injury-related production of cysteinyl leukotrienes contributes to brain damage following experimental traumatic brain injury. J Neurotrauma 26(11):1977-1986

5. Marschallinger J, Schaffner I, Klein B, Gelfert R, Rivera FJ, Illes S et al (2015) Structural and functional rejuvenation of the aged brain by an approved anti-asthmatic drug. Nat Commun 6:8466

6. Yu SY, Zhang XY, Wang XR, Xu DM, Chen L, Zhang LH et al (2014) Cysteinyl leukotriene receptor 1 mediates LTD4-induced activation of mouse microglial cells in vitro. Acta Pharmacol Sin 35(1):33-40

7. Ciccarelli R, D'Alimonte I, Santavenere C, D'Auro M, Ballerini P, Nargi E et al (2004) Cysteinyl-leukotrienes are released from astrocytes and increase astrocyte proliferation and glial fibrillary acidic protein via cys-LT1 receptors and mitogen-activated protein kinase pathway. Eur J Neurosci 20(6):15141524
8. Fang SH, Wei EQ, Zhou Y, Wang ML, Zhang WP, Yu GL et al (2006) Increased expression of cysteinyl leukotriene receptor-1 in the brain mediates neuronal damage and astrogliosis after focal cerebral ischemia in rats. Neuroscience 140(3):969-979

9. Tang SS, Hong H, Chen L, Mei ZL, Ji MJ, Xiang GQ et al (2014) Involvement of cysteinyl leukotriene receptor 1 in Abeta1-42-induced neurotoxicity in vitro and in vivo. Neurobiol Aging 35(3):590-599

10. Biber N, Toklu HZ, Solakoglu S, Gultomruk M, Hakan T, Berkman Z et al (2009) Cysteinyl-leukotriene receptor antagonist montelukast decreases blood-brain barrier permeability but does not prevent oedema formation in traumatic brain injury. Brain Inj 23(6):577-584

11. Lenz QF, Arroyo DS, Temp FR, Poersch AB, Masson CJ, Jesse AC et al (2014) Cysteinyl leukotriene receptor (CysLT) antagonists decrease pentylenetetrazol-induced seizures and blood-brain barrier dysfunction. Neuroscience 277:859-871

12. Zhao R, Shi WZ, Zhang YM, Fang SH, Wei EQ (2011) Montelukast, a cysteinyl leukotriene receptor-1 antagonist, attenuates chronic brain injury after focal cerebral ischaemia in mice and rats. J Pharm Pharmacol 63(4):550-557

13. Michael J, Marschallinger J, Aigner L (2019) The leukotriene signaling pathway: a druggable target in Alzheimer's disease. Drug Discov Today 24(2):505-516

14. Gelosa P, Colazzo F, Tremoli E, Sironi L, Castiglioni L (2017) Cysteinyl Leukotrienes as potential pharmacological targets for cerebral diseases. Mediat Inflamm 2017:3454212

15. Giannopoulos PF, Chu J, Joshi YB, Sperow M, Li JG, Kirby LG et al (2013) 5lipoxygenase activating protein reduction ameliorates cognitive deficit, synaptic dysfunction, and neuropathology in a mouse model of Alzheimer's disease. Biol Psychiatry 74(5):348-356

16. Giannopoulos PF, Chu J, Joshi YB, Sperow M, Li JG, Kirby LG et al (2014) Gene knockout of 5-lipoxygenase rescues synaptic dysfunction and improves memory in the triple-transgenic model of Alzheimer's disease. Mol Psychiatry 19(4):511-518

17. Lai J, Hu M, Wang H, Hu M, Long Y, Miao MX et al (2014) Montelukast targeting the cysteinyl leukotriene receptor 1 ameliorates Abeta1-42induced memory impairment and neuroinflammatory and apoptotic responses in mice. Neuropharmacology 79:707-714

18. Chu J, Li JG, Pratico D (2013) Zileuton improves memory deficits, amyloid and tau pathology in a mouse model of Alzheimer's disease with plaques and tangles. PLoS One 8(8):e70991

19. Sery O, Hlinecka L, Povova J, Bonczek O, Zeman T, Janout V et al (2016) Arachidonate 5-lipoxygenase (ALOX5) gene polymorphism is associated with Alzheimer's disease and body mass index. J Neurol Sci 362:27-32

20. Grinde B, Engdahl B (2017) Prescription database analyses indicates that the asthma medicine montelukast might protect against dementia: a hypothesis to be verified. Immun Ageing 14:20

21. Rozin SI (2017) Case series using Montelukast in patients with memory loss and dementia. Open Neurol J 11:7-10

22. Radmark O, Werz O, Steinhilber D, Samuelsson B (2015) 5-Lipoxygenase, a key enzyme for leukotriene biosynthesis in health and disease. Biochim Biophys Acta 1851(4):331-339

23. Samuelsson B (1983) Leukotrienes: mediators of immediate hypersensitivity reactions and inflammation. Science 220(4597):568-575

24. Lynch KR, O'Neill GP, Liu Q, Im DS, Sawyer N, Metters KM et al (1999) Characterization of the human cysteinyl leukotriene CysLT1 receptor. Nature 399(6738):789-793

25. Heise CE, O'Dowd BF, Figueroa DJ, Sawyer N, Nguyen T, Im DS et al (2000) Characterization of the human cysteinyl leukotriene 2 receptor. J Biol Chem 275(39):30531-30536

26. Ciana P, Fumagalli M, Trincavelli ML, Verderio C, Rosa P, Lecca D et al (2006) The orphan receptor GPR17 identified as a new dual uracil nucleotides/ cysteinyl-leukotrienes receptor. EMBO J 25(19):4615-4627

27. Singh RK, Gupta S, Dastidar S, Ray A (2010) Cysteinyl leukotrienes and their receptors: molecular and functional characteristics. Pharmacology 85(6):336-349

28. Funk CD (2001) Prostaglandins and leukotrienes: advances in eicosanoid biology. Science 294(5548):1871-1875

29. Peters-Golden M, Henderson WR Jr (2007) Leukotrienes. N Engl J Med 357(18):1841-1854

30. Lammers CH, Schweitzer P, Facchinetti P, Arrang JM, Madamba SG, Siggins GR et al (1996) Arachidonate 5-lipoxygenase and its activating protein: prominent hippocampal expression and role in somatostatin signaling. J Neurochem 66(1):147-152 
31. Dagher NN, Najafi AR, Kayala KM, Elmore MR, White TE, Medeiros R et al (2015) Colony-stimulating factor 1 receptor inhibition prevents microglial plaque association and improves cognition in 3xTg-AD mice. J Neuroinflammation 12:139

32. Spangenberg EE, Lee RJ, Najafi AR, Rice RA, Elmore MR, Blurton-Jones $M$ et al (2016) Eliminating microglia in Alzheimer's mice prevents neuronal loss without modulating amyloid-beta pathology. Brain 139(Pt 4):1265-1281

33. Jankowsky $\lrcorner$, Slunt $H H$, Ratovitski $T$, Jenkins NA, Copeland NG, Borchelt DR (2001) Co-expression of multiple transgenes in mouse CNS: a comparison of strategies. Biomol Eng 17(6):157-165

34. Jankowsky JL, Fadale DJ, Anderson J, Xu GM, Gonzales V, Jenkins NA et al (2004) Mutant presenilins specifically elevate the levels of the 42 residue beta-amyloid peptide in vivo: evidence for augmentation of a 42 -specific gamma secretase. Hum Mol Genet 13(2):159-170

35. Unger MS, Schernthaner P, Marschallinger J, Mrowetz $H$, Aigner L (2018) Microglia prevent peripheral immune cell invasion and promote an antiinflammatory environment in the brain of APP-PS1 transgenic mice. J Neuroinflammation 15(1):274

36. Unger MS, Marschallinger J, Kaindl J, Hofling C, Rossner S, Heneka MT et al (2016) Early changes in hippocampal neurogenesis in transgenic mouse models for Alzheimer's disease. Mol Neurobiol 53(8):5796-5806

37. Marschallinger J, Sah A, Schmuckermair C, Unger M, Rotheneichner $P$, Kharitonova $\mathrm{M}$ et al (2015) The L-type calcium channel Cav1.3 is required for proper hippocampal neurogenesis and cognitive functions. Cell Calcium 58(6):606-616

38. Schnell SA, Staines WA, Wessendorf MW (1999) Reduction of lipofuscin-like autofluorescence in fluorescently labeled tissue. J Histochem Cytochem 47(6):719-730

39. Braak H, Alafuzoff I, Arzberger T, Kretzschmar H, Del Tredici K (2006) Staging of Alzheimer disease-associated neurofibrillary pathology using paraffin sections and immunocytochemistry. Acta Neuropathol 112(4):389-404

40. Braak H, Braak E (1991) Neuropathological stageing of Alzheimer-related changes. Acta Neuropathol 82(4):239-259

41. Mirra SS, Heyman A, McKeel D, Sumi SM, Crain BJ, Brownlee LM et al (1991) The consortium to establish a registry for Alzheimer's disease (CERAD). Part II. Standardization of the neuropathologic assessment of Alzheimer's disease. Neurology 41(4):479-486

42. McKeith IG, Dickson DW, Lowe J, Emre M, O'Brien JT, Feldman H et al (2005) Diagnosis and management of dementia with Lewy bodies: third report of the DLB consortium. Neurology 65(12):1863-1872

43. Montine TJ, Phelps CH, Beach TG, Bigio EH, Cairns NJ, Dickson DW et al (2012) National Institute on Aging-Alzheimer's Association guidelines for the neuropathologic assessment of Alzheimer's disease: a practical approach. Acta Neuropathol 123(1):1-11

44. Thal DR, Rub U, Orantes M, Braak H (2002) Phases of a beta-deposition in the human brain and its relevance for the development of AD. Neurology 58(12):1791-1800

45. Andrews S (2010) FastQC: a quality control tool for high throughput sequence data [online]

46. Langmead B, Salzberg SL (2012) Fast gapped-read alignment with bowtie 2 . Nat Methods 9(4):357-359

47. Anders S, Pyl PT, Huber W (2015) HTSeq--a Python framework to work with high-throughput sequencing data. Bioinformatics 31(2):166-169

48. Love Ml, Huber W, Anders S (2014) Moderated estimation of fold change and dispersion for RNA-seq data with DESeq2. Genome Biol 15(12):550

49. Durinck S, Spellman PT, Birney E, Huber W (2009) Mapping identifiers for the integration of genomic datasets with the R/bioconductor package biomaRt. Nat Protoc 4(8):1184-1191

50. Spangenberg E, Severson PL, Hohsfield LA, Crapser J, Zhang J, Burton EA et al (2019) Sustained microglial depletion with CSF1R inhibitor impairs parenchymal plaque development in an Alzheimer's disease model. Nat Commun 10(1):3758

51. Henry RJ, Ritzel RM, Barrett JP, Doran SJ, Jiao Y, Leach JB et al (2020) Microglial depletion with CSF1R inhibitor during chronic phase of experimental traumatic brain injury reduces neurodegeneration and neurological deficits. J Neurosci 40(14):2960-2974

52. Seitz S, Clarke P, Tyler KL (2018) Pharmacologic depletion of microglia increases viral load in the brain and enhances mortality in murine models of flavivirus-induced encephalitis. J Virol 92(16):e00525-18. https://doi.org/ 10.1128/JVI.00525-18
53. Nissen JC, Thompson KK, West BL, Tsirka SE (2018) Csf1R inhibition attenuates experimental autoimmune encephalomyelitis and promotes recovery. Exp Neurol 307:24-36

54. Spangenberg EE, Green KN (2017) Inflammation in Alzheimer's disease: lessons learned from microglia-depletion models. Brain Behav Immun 61:1-11

55. Bennett ML, Bennett FC, Liddelow SA, Ajami B, Zamanian JL, Fernhoff NB et al (2016) New tools for studying microglia in the mouse and human CNS. Proc Natl Acad Sci U S A 113(12):E1738-E1746

56. Peters-Golden M, Brock TG (2001) Intracellular compartmentalization of leukotriene synthesis: unexpected nuclear secrets. FEBS Lett 487(3):323-326

57. Kulkarni S, Das S, Funk CD, Murray D, Cho W (2002) Molecular basis of the specific subcellular localization of the C2-like domain of 5-lipoxygenase. J Biol Chem 277(15):13167-13174

58. Uz T, Pesold C, Longone P, Manev H (1998) Aging-associated up-regulation of neuronal 5-lipoxygenase expression: putative role in neuronal vulnerability. FASEB J 12(6):439-449

59. Rius B, Lopez-Vicario C, Gonzalez-Periz A, Moran-Salvador E, Garcia-Alonso V, Claria J et al (2012) Resolution of inflammation in obesity-induced liver disease. Front Immunol 3:257

60. Bannenberg G, Serhan CN (2010) Specialized pro-resolving lipid mediators in the inflammatory response: an update. Biochim Biophys Acta 1801(12): $1260-1273$

61. Wang X, Zhu M, Hjorth E, Cortes-Toro V, Eyjolfsdottir H, Graff C et al (2015) Resolution of inflammation is altered in Alzheimer's disease. Alzheimers Dement 11(1):40-50.e1-2

62. Nunns GR, Stringham JR, Gamboni F, Moore EE, Fragoso M, Stettler GR et al (2018) Trauma and hemorrhagic shock activate molecular association of 5lipoxygenase and 5-lipoxygenase-activating protein in lung tissue. J Surg Res 229:262-270

63. Loell I, Alemo Munters L, Pandya J, Zong M, Alexanderson H, Fasth AE et al (2013) Activated LTB4 pathway in muscle tissue of patients with polymyositis or dermatomyositis. Ann Rheum Dis 72(2):293-299

64. Bonham LW, Sirkis DW, Yokoyama JS (2019) The transcriptional landscape of microglial genes in aging and neurodegenerative disease. Front Immunol 10:1170

65. Masuda T, Sankowski R, Staszewski O, Bottcher C, Amann L, Sagar et al (2019) Spatial and temporal heterogeneity of mouse and human microglia at single-cell resolution. Nature 566(7744):388-392

66. Stratoulias V, Venero JL, Tremblay ME, Joseph B (2019) Microglial subtypes: diversity within the microglial community. EMBO J 38(17):e101997

67. Keren-Shaul H, Spinrad A, Weiner A, Matcovitch-Natan O, Dvir-Szternfeld R, Ulland TK et al (2017) A unique microglia type associated with restricting development of Alzheimer's disease. Cell 169(7):1276-1290 e17

68. Marschallinger J, Iram T, Zardeneta M, Lee SE, Lehallier B, Haney MS et al (2020) Lipid-droplet-accumulating microglia represent a dysfunctional and proinflammatory state in the aging brain. Nat Neurosci 23(2):194-208

69. Wang Y, Cella M, Mallinson K, Ulrich JD, Young KL, Robinette ML et al (2015) TREM2 lipid sensing sustains the microglial response in an Alzheimer's disease model. Cell 160(6):1061-1071

70. Zhang Y, Chen K, Sloan SA, Bennett ML, Scholze AR, O'Keefe S, Phatnani HP, Guarnieri P, Caneda C, Ruderisch N, Deng S, Liddelow SA, Zhang C, Daneman R, Maniatis T, Barres BA, Wu JQ (2014) An RNA-Seq transcriptome and splicing database of glia, neurons, and vascular cells of the cerebral cortex. J Neurosci 34(36):11929-11947

71. Zhang Y, Sloan SA, Clarke LE, Caneda C, Hayden-Gephart M, Grant GA, Cheshier SH, Edwards MS, Chang EF, Li G, Steinberg GK, Vogel H, Blumenthal PD, Barres BA (2016) Purification and Functional Characterization of Human Astrocytes. Neuron. 89(1):37-53

72. Reid GK, Kargman S, Vickers PJ, Mancini JA, Leveille C, Ethier D et al (1990) Correlation between expression of 5-lipoxygenase-activating protein, 5lipoxygenase, and cellular leukotriene synthesis. J Biol Chem 265(32):19818-19823

73. Radmark O, Werz O, Steinhilber D, Samuelsson B (2007) 5-Lipoxygenase: regulation of expression and enzyme activity. Trends Biochem Sci 32(7):332-341

74. Schmider AB, Vaught M, Bauer NC, Elliott HL, Godin MD, Ellis GE et al (2019) The organization of leukotriene biosynthesis on the nuclear envelope revealed by single molecule localization microscopy and computational analyses. PLoS One 14(2):e0211943

75. Chu LS, Fang SH, Zhou Y, Yu GL, Wang ML, Zhang WP et al (2007) Minocycline inhibits 5-lipoxygenase activation and brain inflammation after focal cerebral ischemia in rats. Acta Pharmacol Sin 28(6):763-772

76. Maas SLN, Breakefield XO, Weaver AM (2017) Extracellular vesicles: unique intercellular delivery vehicles. Trends Cell Biol 27(3):172-188 
77. Boilard E (2018) Extracellular vesicles and their content in bioactive lipid mediators: more than a sack of microRNA. J Lipid Res 59(11):2037-2046

78. Esser J, Gehrmann U, D'Alexandri FL, Hidalgo-Estevez AM, Wheelock CE, Scheynius A et al (2010) Exosomes from human macrophages and dendritic cells contain enzymes for leukotriene biosynthesis and promote granulocyte migration. J Allergy Clin Immunol 126(5):1032-1040 1040 e1-4

79. Fumagalli M, Lecca D, Coppolino GT, Parravicini C, Abbracchio MP (2017) Pharmacological properties and biological functions of the GPR17 receptor, a potential target for neuro-regenerative medicine. Adv Exp Med Biol 1051: 169-192

\section{Publisher's Note}

Springer Nature remains neutral with regard to jurisdictional claims in published maps and institutional affiliations.

Ready to submit your research? Choose BMC and benefit from:

- fast, convenient online submission

- thorough peer review by experienced researchers in your field

- rapid publication on acceptance

- support for research data, including large and complex data types

- gold Open Access which fosters wider collaboration and increased citations

- maximum visibility for your research: over $100 \mathrm{M}$ website views per year

At $\mathrm{BMC}$, research is always in progress.

Learn more biomedcentral.com/submissions 